\title{
A study on the assessment of traffic noise induced annoyance and awareness levels about the potential health effects among residents living around a noise-sensitive area
}

\author{
Towseef Ahmed Gilani ${ }^{1}$ (D) Mohammad Shafi Mir $^{2}$ (D) \\ Received: 27 March 2021 / Accepted: 25 June 2021 / Published online: 3 July 2021 \\ (C) The Author(s), under exclusive licence to Springer-Verlag GmbH Germany, part of Springer Nature 2021
}

\begin{abstract}
The present cross-sectional study aimed to evaluate the risk factors for traffic noise-induced annoyance and also assess the awareness levels among the exposed population concerning the health impacts caused by traffic noise. Field measurements were made to validate the application of the standard noise models, which were later used to present the acoustical environment and assess the exposure level around a super-speciality hospital surrounded by a residential zone. Results from the noise maps and façade maps revealed that the area was exposed to noise levels exceeding the upper safe limits by more than $10 \mathrm{~dB}(\mathrm{~A})$. The effect of exposure in the form of annoyance and the awareness level were evaluated using a questionnaire survey in a sample of 565 residents. Attention questions were incorporated in the questionnaire, and the awareness level was evaluated using the mean awareness index score. Respondents living in noisy areas were having a higher risk for annoyance as compared to those living in quiet areas $(\mathrm{OR}=4.06 ; 95 \% \mathrm{CI}=2.79-5.88)$. Reporting poor sleep quality, being sensitive to noise, and noise perception at home were the significant risk factors for annoyance. Most of the respondents were classified as having no/little awareness about serious health ailments caused by traffic noise. Lower awareness levels, despite a higher literacy rate and a higher percentage of the young population, imply that there is a need for undertaking mass awareness programmes so that the impacts can be reduced to a minimum, if not eliminated.
\end{abstract}

Keywords Annoyance $\cdot$ Public health $\cdot$ Noise maps $\cdot$ Sleep disturbance, Mean awareness index score

\section{Introduction}

Over the years, environmental noise levels have grown to such an extent that they can cause degradation of a region's acoustic environment and severely impact public health (Seidman and Standring 2010; de Paiva Vianna et al. 2015). Despite its ubiquitous nature, the properties of being invisible without any residual effect, and people becoming accustomed to it,

Responsible Editor: Lotfi Aleya

Towseef Ahmed Gilani

tawseef_46phd15@nitsri.ac.in

1 Department of Civil Engineering, National Institute of Technology, Srinagar J \& K 190006, India

2 Transportation \& Planning Section, Department of Civil Engineering, National Institute of Technology, Srinagar J \& K 190006, India environmental noise is the most underrated pollutant (Basner et al. 2014). According to a study by Hänninen et al. (2014), environmental noise is the second most serious risk factor affecting the health of Europe's population and contributes nearly $8 \%$ of the total burden of disease. According to a review of END (Environmental Noise Directive, 2002), about 120 million of the European population are exposed to traffic noise levels greater than $55 \mathrm{~dB}(\mathrm{~A})$, which is considered to be the safe level for preventing any serious impact due to traffic noise on public health. The review also reported that nearly 10,000 premature deaths occur annually in Europe due to traffic noise (European Environmental Agency Report, 2014). Due to urbanization, the past few decades have experienced a rapid increase in the number of vehicles plying on roads, and this has led to the degradation of the acoustic quality of the environment in urban areas (Méline et al. 2013). Most of the research aimed at controlling noise levels focuses on the transportation sources. Transportation in general and road traffic, in particular, are considered to be the most 
significant contributor to environmental noise pollution (Hamad et al. 2017). This is probably due to the vast reach of the road traffic infrastructure as compared to railways and air traffic. Environmental noise is a concern for many developing (Essandoh and Armah 2011; Mehdi et al. 2011; Khaiwal et al. 2016) as well as developed nations like the USA and many European nations (Hammer et al. 2014; Park et al. 2018b). The complicating component in developing countries is the irregular and unplanned growth in household locations and transport infrastructure. This mostly results in households clustering around the transportation infrastructures like highways, airports, and railway stations, thereby increasing the residents' duration and frequency of exposure (Jones et al. 2015; Lee 2018; Traoré 2019). According to WHO (World Health Organization), robust industrialization and the transport system's growth are significant causes of noise pollution (Brown and van Kamp 2017). RTN (road traffic noise) in the most impacting noise source of the modern lifestyle (Ruiz-Padillo et al. 2016). Although the parameters influencing the emission of noise usually considered include vehicle engines and flow composition, studies have also established "acoustic impedance of road surfaces" (Bianco et al. 2020; Praticò et al. 2021), "type of vehicle tyres" (Licitra et al. 2017), "pavement ageing" (Teti et al. 2020), and "pavement texture and material" (Praticò and AnfossoLédée 2012; Praticò 2014; Del Pizzo et al. 2020; de León et al. 2020) as other important parameters that should be considered.

A significant number of studies have established the relation between traffic noise and physical, psychological, and physiological outcomes (Stansfeld and Matheson 2003; Pathak et al. 2008; Rahmani et al. 2011; Basner et al. 2014; Jagniatinskis et al. 2016; Basner and McGuire 2018). Traffic noise has been found to interfere with day-to-day activities, resulting in annoyance (Miedema and Oudshoorn 2001), hearing damage (Stansfeld et al. 2000), sleep disorders (Muzet 2007; Halperin 2014), learning impairment (Lercher et al. 2003; Minichilli et al. 2018), heart diseases (Dratva et al. 2010, 2012; van Kempen and Babisch 2012), metabolic diseases like diabetes (Nicole 2013; Clark et al. 2017), and even cancer (Roswall et al. 2017). RTN exposure has also been associated with the usage of psychotropic medication use (Okokon et al. 2018). The negative impacts of traffic noise include both short-term and long-term effects; however, one of the most important outcomes is annoyance (Dratva et al. 2010; WHO 2011). Annoyance refers to negative feelings like displeasure, disturbance, discontent, and uneasiness which finally manifests in the form of anxiety and stress. The levels of annoyance are often used to reflect the somatic damage caused by traffic noise (Babisch 2002). Although environmental noise comprises many components, evidence has emerged that traffic noise is the major component of environmental noise (OUIS D, 2001; Ali and Tamura 2003; Ising and
Kruppa 2004). In fact, traffic noise-induced annoyance has been termed as a precursor for other serious health ailments (van Kempen et al. 2002; Rylander 2004; Leon Bluhm et al. 2006). However, the research studies highlighting the association between RTN and annoyance have mostly remained limited to developed countries. Very small number of studies have been reported from developing countries (Agarwal and Swami 2011). According to Banerjee (2012), studies reporting the association between traffic noise exposure and annoyance in terms of effect indicators have never been reported from India. Even if studies have been conducted in developing countries, the assessment of noise levels has been based on measuring noise levels at few locations and expressing the effects using linear regression. The usage of noise maps for depicting the acoustic environment of the surrounding areas has been limited (Debnath and Singh 2018).

The management of the traffic noise and its impacts involves 3 main steps. These include "assessment of the traffic noise levels in a given study area", "evaluation of the effect due to exposure to traffic noise", and "assessment of the awareness among the general population concerning the effects of noise pollution". Studies have reported RTN levels in different study areas across the globe and also the assessment of the effects due to exposure to RTN. The work in these two directions has mostly remained concentrated in developed countries, and less work has been reported from developing nations like India. However, the research work regarding the assessment of awareness level among the exposed population has not been evaluated to a great extent. Having prior knowledge about the level of awareness among the common masses can serve better in reducing the impacts of RTN. Traffic noise may have varying levels of impacts depending upon the level of importance attached to the region or study area. Studies reporting the negative outcomes due to traffic noise and noise maps can prove extremely beneficial for the regulating authorities in framing the policies for the improvement of the acoustic environment and reducing the traffic noise impacts on the exposed population especially around noise-sensitive areas like hospitals, schools/colleges, and offices. To the best of our knowledge, this research gap has not been addressed to the desired extent for Indian conditions. Realizing the importance of such works in providing a useful addition to the existing literature, the present study was conducted in an urban noise-sensitive area of North India. The study had three primary objectives. First was the assessment of the RTN levels around a noise-sensitive area in an urban setting (the study area in our case). Second was the evaluation of the extent of RTN-induced annoyance among the exposed population, the most significant contributors, and also the associated risks. Thirdly, the study aimed to evaluate the awareness levels among the residents living in the study area concerning the potential health effects that can be caused by RTN. The study aimed at achieving the primary objectives through on-field 
noise measurements, questionnaire surveys, and also using statistical procedures for modelling purposes. A piece of detailed information about these steps is given in the "Methodology of the study" section.

\section{Methodology of the study}

The methodology of the study is shown in the form of a flowchart in Figure 1.

\section{Study area}

Srinagar City, once known as the "Venice of East", due to its picturesque and mesmerizing beauty, is the most visited and famous destinations for both national and international tourists. The city covers an area of $295 \mathrm{~km}^{2}$ with the coordinates of $33^{\circ}$ $59^{\prime} 14^{\prime \prime} \mathrm{N}$ and $34^{\circ} 12^{\prime} 37^{\prime \prime} \mathrm{N}$ latitude and $74^{\circ} 41^{\prime} 06^{\prime \prime} \mathrm{E}$ and $74^{\circ}$ $57^{\prime} 27^{\prime \prime} \mathrm{E}$ longitude with an elevation of $1580 \mathrm{~m}$ above the mean sea level. The population of the city was 1.23 million in 2011 and was estimated to be around 1.81 million for 2019 with an average annual growth rate of $1.83 \%$ (Mushtaq et al. 2020). The city has witnessed an influx of citizens from rural areas owing to the availability of health, employment opportunities, and other facilities. Unplanned urban management of the city has led to serious negative impacts on the environment and the standard of life of the residents. Owing to the large size of the city, we selected the Karanagar area, located barely $2 \mathrm{~km}$ away from the centre of the city, for performing noise measurements and conducting the questionnaire survey. The study area witnesses a high traffic volume (including commercial, private, and public transport) and inflow movement of pedestrians owing to the presence of some famous commercial areas, medical colleges, and a super-speciality hospital. The study area also consists of a residential zone in the immediate vicinity. The area experiences frequent traffic congestion and high noise levels. The population living in the close vicinity, up to $250 \mathrm{~m}$ from the main road, was chosen for the survey.

\section{Noise exposure assessment}

Generally, two methods are available for assessing traffic noise levels. The first method involves measuring noise levels using a sound level meter, and the other consists of modelling the noise levels using the available standard models. The problem of the first method is regarding the availability of the required number of sound level meters while the second method involves the usage of standard noise calculation models developed predominantly for developed countries, and due to the difference in traffic conditions in India, the application of these methods may be limited. Due to the availability of only one sound level meter, the problem was overcome by first measuring the daytime and night-time noise levels using a class 1 sound level meter, which was calibrated using a class 1 acoustic calibrator, near 41 preselected sites as shown in Figure 2 for $24 \mathrm{~h}$ each (7:00 a.m. to 10:00 p.m. and 10:00 p.m. to 7:00 a.m.). The measurements were conducted from 1 October 2020 to 7 December 2020. The measurements were made following the recommendations of ISO 1996 (ISO 2003, 2007). This involves placing the microphone $1.5 \mathrm{~m}$ above the ground level and at a distance of $2 \mathrm{~m}$ in front of the most exposed façade. The time frame was selected as per the definition of the $\mathrm{L}_{\mathrm{DN}}$ (day-night average sound level) index (Héritier et al. 2017) given as

$L_{D N}=L_{A E}+10 \times \log _{10}\left(N_{D A Y}+10 \times N_{N I G H T}\right)-49.4$,

where $L_{A E}$ is the A-weighted equivalent noise level measured for the given time interval ( $24 \mathrm{~h}$ in the study). $N_{D A Y}$ is the number of vehicles passing by between 7:00 a.m. and 10:00 p.m., and $N_{N I G H T}$ is the number of vehicles passing by between 10:00 p.m. and 7:00 a.m. An extra 10-dB penalty is applied to nighttime (10:00 p.m. to 7:00 a.m.). A null hypothesis was made for validating a standard noise prediction model provided in the SoundPLAN® version 8.2 software package. The null hypothesis made was "there is no significant difference between the two groups of noise levels, i.e. one measured in the field and the other obtained from the software". Both modelled and measured noise levels were tested for normal distribution using the KolmogorovSmirnov test as well as Shapiro-Wilk test. The results from the tests are shown in Table 1. As both tests resulted in nonsignificant values ( $p$-value $>0.05$ ), the noise level data were therefore compared using paired sample t-test for testing the null hypothesis. A significance level of $95 \%$ was chosen. Based on a study conducted in Lucknow, India, we selected the TNM 2.5 model developed by FHWA (Federal Highway Administration) for modelling the noise levels using data related to traffic and pavements (Shukla et al. 2009). A scatter plot between the measured and modelled noise levels and the results from the paired sample t-test are shown in Figure 3 and Table 2, respectively. Both the scatter plot and paired sample t-test showed good agreement between the measured and modelled noise levels; hence, we used the TNM 2.5 model for generating noise map and façade map of the study area. Based on the literature review, we hypothesized that "higher traffic noise exposure was associated with higher noise annoyance". We divided the study area into a "noisy area" and a "quiet area" based on the average cutoff value of $55 \mathrm{~dB}(\mathrm{~A})$, prescribed by WHO (2011) as well as CPCB (Central Pollution Control Board) in India. This is shown in Table 3.

\section{Inputs required for TNM 2.5}

The input to modelling procedure involves using trafficrelated information like classified traffic volume count, traffic speed, pavement material type, pavement width, presence of traffic control devices, and presence of any bridge structures. 


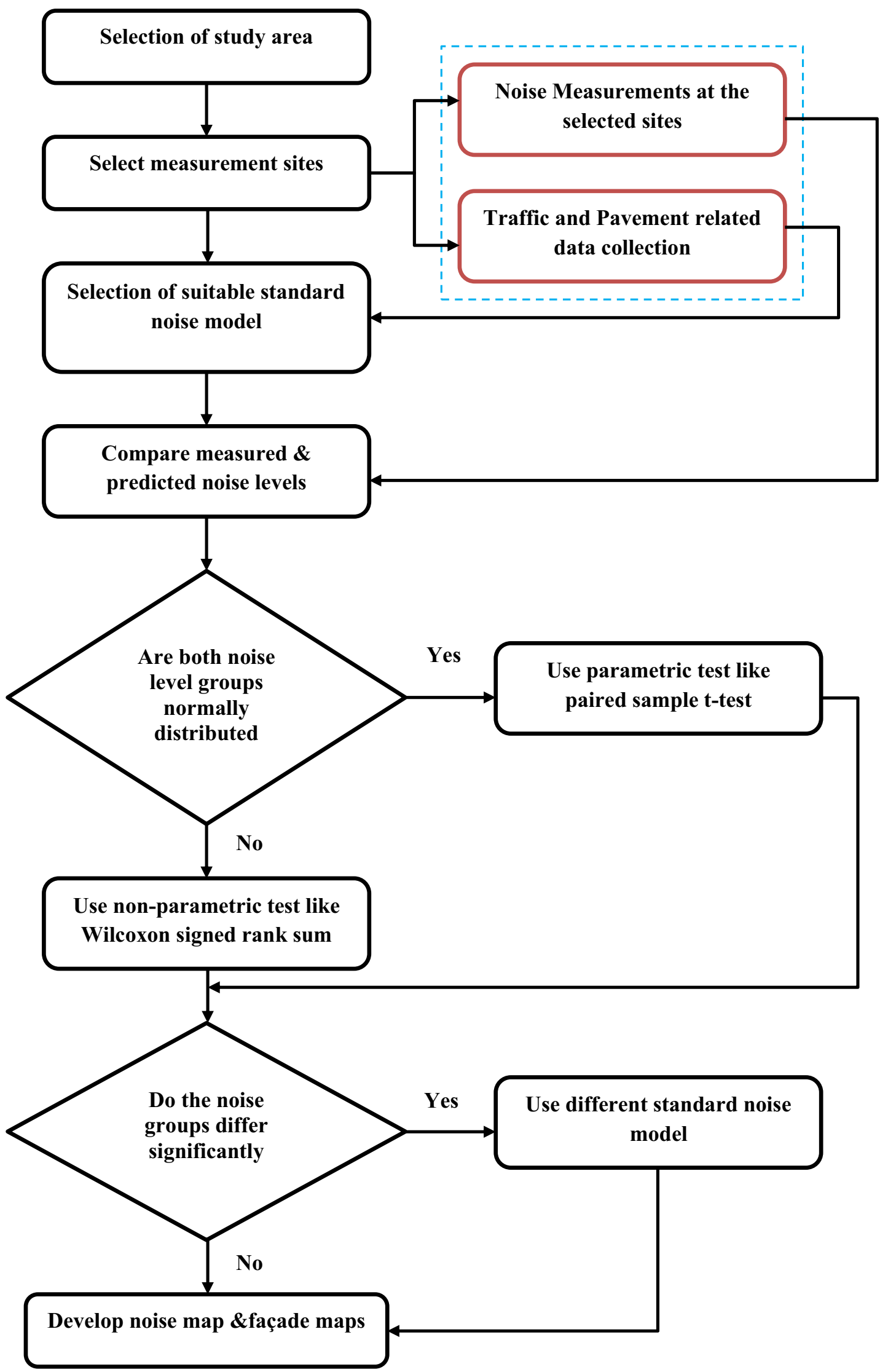

Fig. 1 Flowchart depicting the methodology of the study 


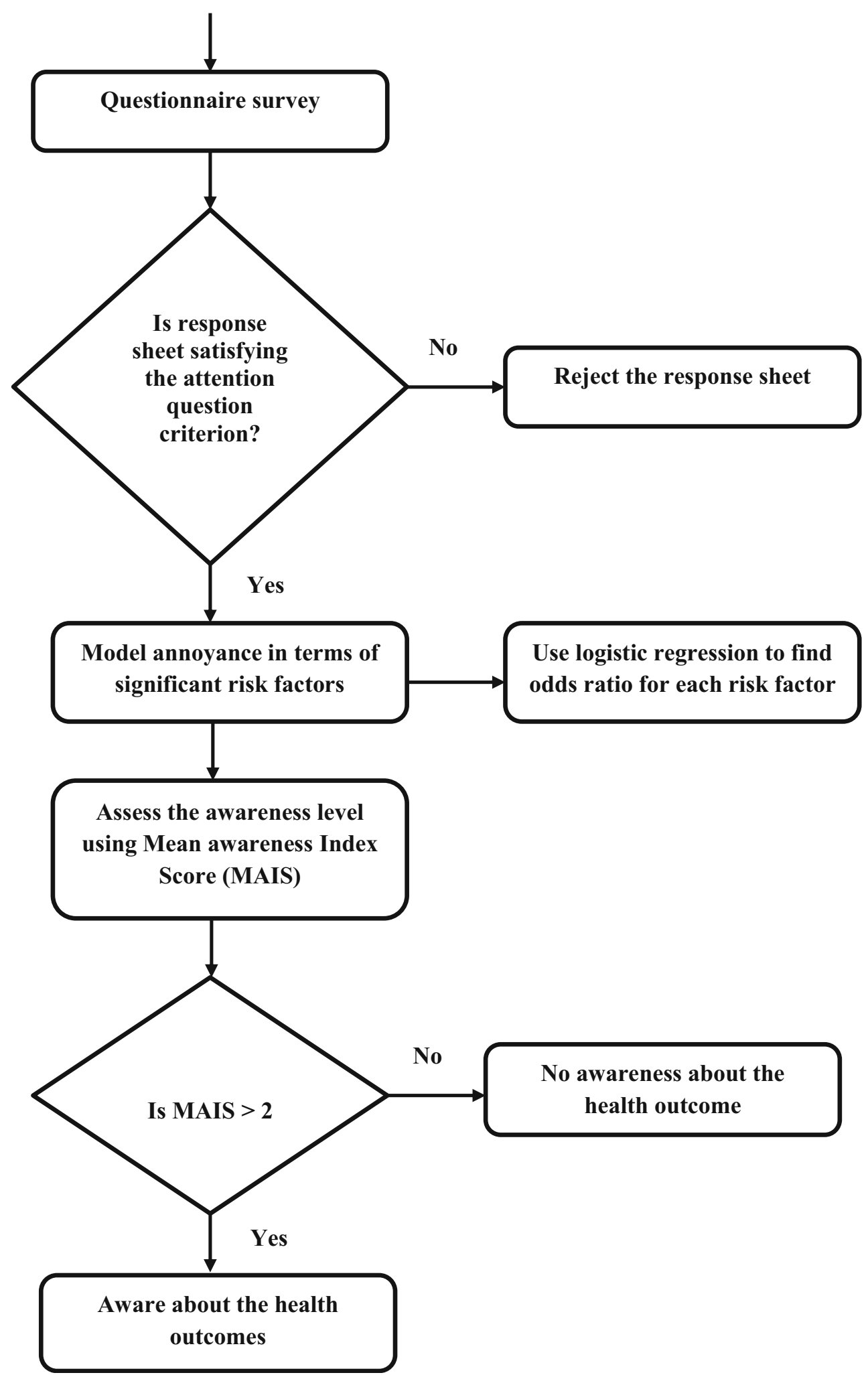

Fig. 1 (continued) 
Table 1 Normality test for the continuous variables age, body mass index, stress score, and day-night noise level

\begin{tabular}{lllllllll}
\hline Variable & \multicolumn{3}{l}{ Kolmogorov-Smirnov } & & \multicolumn{2}{l}{ Shapiro-Wilk } \\
\cline { 2 - 3 } & Statistic & df & p-value & & Statistic & df & p-value \\
\hline Measured noise level & 0.082 & 41 & 0.200 & & 0.983 & 41 & 0.782 \\
Modelled noise level & 0.067 & 41 & 0.200 & & 0.986 & 41 & 0.889 \\
\hline
\end{tabular}

\section{Classified traffic volume count, traffic speed, pavement material, and pavement width data}

Traffic count for the different kinds of vehicles was done using a videographic survey in which a camera was mounted on a suitable and safe location near the study site, and recordings were taken for the complete $24 \mathrm{~h}$. The camera (GoPro Hero 8 CHDHX-801), capable of recording even during night hours, was used. The recordings were transferred to a computer, and the volume count for each kind of vehicle was obtained manually. At each of the preselected sites, a marking of $100 \mathrm{~m}$ was drawn and the time taken by vehicles to cover this distance was obtained from the video. This procedure helped in obtaining the average traffic speed of the vehicles. Pavement material-related information and pavement width were directly obtained from the sites. The presence or absence of traffic control devices was also obtained from the study sites.

\section{Generation of the noise map}

A noise map helps in visualizing the noise/acoustic environment of an area with the help of contour lines or the fill pattern following the user-defined colour scale at a certain predefined height above the ground level. In the present study, a noise map of the study area was developed using a grid space of $5 \mathrm{~m}$ and at a height of $2 \mathrm{~m}$ from the ground level. The field size was selected to be $(9 \times 9) \mathrm{m}$, and a threshold value of $40 \mathrm{~dB}(\mathrm{~A})$ was selected below which interpolation was followed.

\section{Generation of the façade noise map}

A façade noise map is generated to depict the noise levels reaching the facades of the buildings in a given area. In the present study, the exposure levels of the respondents were obtained from the façade map drawn for the study area. The
Table 3 Cut-off values for various types of areas prescribed in India by CPCB (2001)

\begin{tabular}{lll}
\hline Type of area & Noise level, dB(A) \\
\cline { 2 - 3 } & Daytime & $\begin{array}{l}\text { Night- } \\
\text { time }\end{array}$ \\
\hline Industrial area & 75 & 70 \\
Commercial area & 65 & 55 \\
Residential area & 55 & 45 \\
Silence zone & 50 & 40 \\
\hline
\end{tabular}

procedure involved placing one receiver in the centre of the façade, and the distance to the façade was selected to be 0.01 $\mathrm{m}$. The height of the buildings needed as input in the model was obtained through field visits of the study area. A screenshot for defining the various parameters used for developing the noise map and the façade map is shown in Figure 4. A similar procedure has been used in other studies as well (Murphy and Douglas 2018; Park et al. 2018b; Foraster et al. 2018; Gilani and Mir 2021).

\section{Sample size determination}

As the study utilized the logistic regression analysis for identifying the potential risk factors of traffic noise annoyance, the sample size was determined using the a priori power analysis. We used Gpower version 3.1.9.4 for the calculation of sample size. The significance level $\alpha$ was chosen to be 0.05 , while the power of the study was chosen to be 0.80 . Concerning the effect size, no previous literature was found by the authors. Therefore, a pilot study, comprising of 40 participants, was conducted for which the effect size in terms of odds ratio was evaluated. The odds ratio was found to be 1.59 . The squared multiple correlation coefficient between the main predictor (i.e. traffic noise) and all other covariates was obtained by regressing the main predictor onto the data for all other covariates. Its value was found to be 0.38 . The final value of the sample size was calculated to be 555 . The final sample size obtained, however, was 565. A plot for calculating the sample size using a specified value of power and effect size is shown in Figure 5. As per Census 2011, the selected sample was a good representative of the city in terms of demographic characteristics like age, gender, literacy rate, and marital status.
Table 2 Output from the paired sample t-test for checking any significant difference between measured and predicted noise levels

\begin{tabular}{llllllll}
\hline Variable & Mean & Std. deviation & $95 \%$ CI & & t statistic & df & Sig. (2-tailed) \\
\hline$(\mathrm{MNL}-\mathrm{MoNL})$ & 0.12 & 0.99 & -0.195 & 0.434 & 0.766 & 40 & 0.448 \\
\hline
\end{tabular}

$M N L$ Measured noise level, MoNL Modelled noise level 


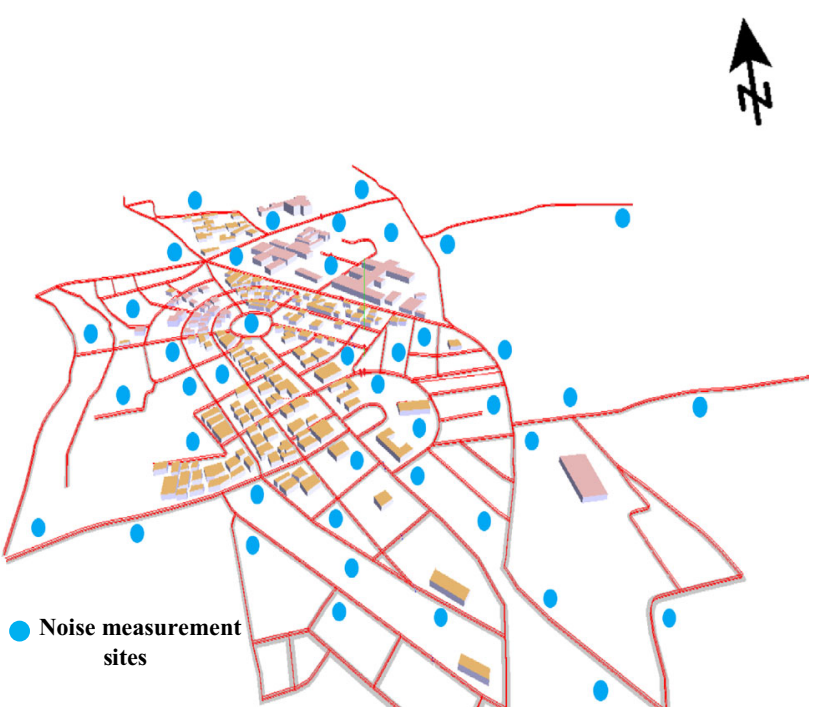

Fig. 2 A 3D view of the study area with the preselected 41 noise measuring sites

\section{Questionnaire survey}

A random sampling approach was used for collecting the data. In this direction, we utilized the house numbers that were assigned to each house in the surrounding area by SMC (Srinagar Municipal Corporation). All the residential house numbers ranged between 1 and 265. The range of (1 to 300) was entered into an online sequence generator, and as per the sequence generated, we selected the households for the questionnaire survey. If the sequence number turned out to be not representing any household, it was neglected and the next one was selected. An inclusion criterion based on residence period was also used, according to which only those respondents who had been living at their current address for more than 1 year were selected. A pilot study was first conducted to test the questionnaire (Online resource) with 20 participants for any improvements, who were later excluded from the main study. The survey team visited the households selected for the study, and after they socialized with

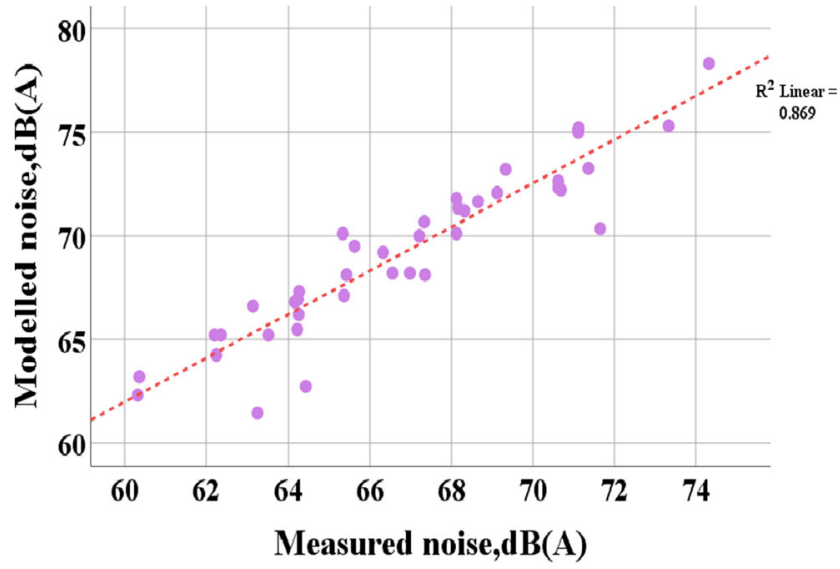

Fig. 3 Scatter plot of the measured and modelled noise levels at the 41 preselected measurement sites the elders of the family, the purpose of the study and how it can prove beneficial for the society were explained in the local Kashmiri language. The members distributed the questionnaires and encouraged all the residents to participate and return the completed questionnaires. The participation was completely voluntary, and no incentives were offered to the respondents. Participants were assured about the privacy of their personal information. A total of 565 response sheets were obtained. Information about the demographic characteristics including age, gender, duration of residence/work, marital status, and educational background was obtained. Information about any underlying chronic disease was also obtained. Noise sensitivity, which is considered to be an important mediating factor for road traffic noise induced annoyance, was evaluated using the modified 16item noise sensitivity scale proposed by Weinstein (Vastfjall 2002). It consists of responding to various statements on a Likert scale of 1 (meaning not at all) to 7 (meaning very much). The questionnaire consisted of three reverse-coded questions, and while evaluating the final sensitivity score, the response was subtracted from " 8 " to ensure the classification capability of the questionnaire. Respondents with a sensitivity score greater than 64 were classified as highly noise sensitive, and those below 64 were classified as less sensitive. Noise annoyance was assessed following the recommendations provided by ISO/TS15666 , using two scales. One is the 5-point verbal scale for the question "Thinking about the past 12 months or so, when you are at home/place of work, how much does noise from road traffic bother, disturb, or annoy you?" The numerical scale consisted of rating the question "Thinking about the past 12 months or so, what number from 0 to 10 best shows how much you were bothered, disturbed, or annoyed by road traffic noise?" 0 meant not at all bothered, and 10 meant extremely bothered.

The questionnaire enquired about the perception of noise at home or place of work and also evaluated the awareness level about traffic noise-related health effects. Six statements about the various ill effects of traffic noise on human health reported in the literature were framed, and the level of agreement was evaluated on a Likert scale of 1 to 5, with 1 meaning "not at all" and 5 meaning "completely agree". This is shown in Table 4. To evaluate the MAIS (mean awareness index score) of each respondent, the average score was calculated for all six statements. The minimum and maximum values could range from 1 to 5 . A self-introduced cut-off value $>2$ was chosen for classifying the respondents as being aware or not aware of the ill effects of traffic noise. One of the important prerequisites of the questionnaire survey is ensuring that respondents pay full attention while filling the items. To ensure this we used "attention questions" in our survey. Three attention questions were used in the questionnaire. The three attention questions were simple arithmetic questions that do not require any special knowledge or skill (Online resource). Any response sheet having three incorrect replies was excluded from further analysis. Such an approach was used in one of our previous works 


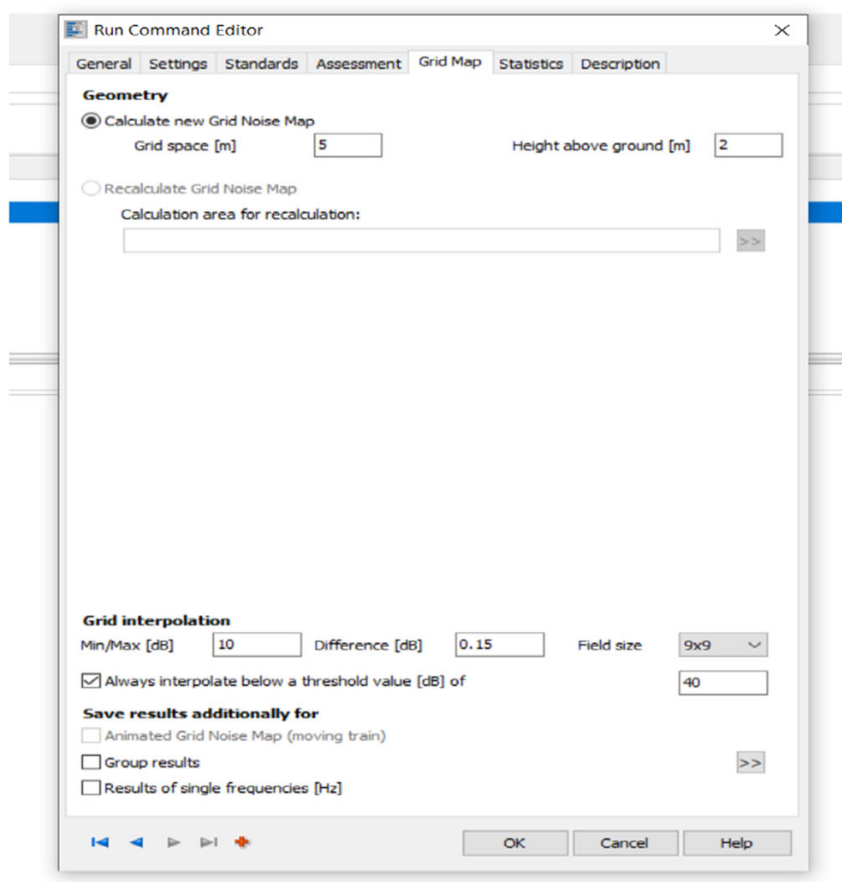

(a)

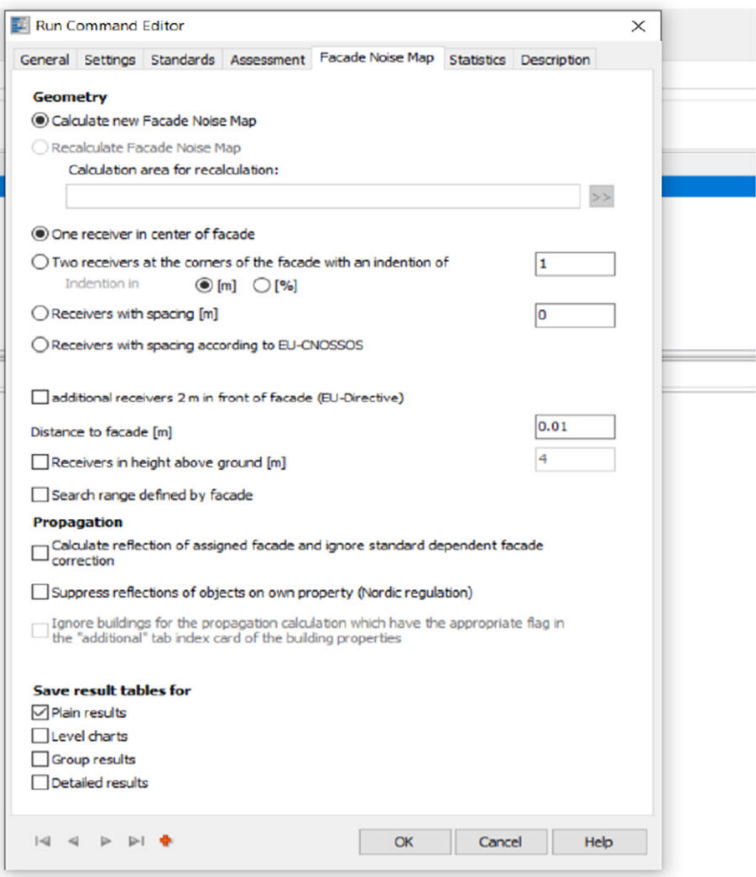

(b)

Fig. 4 Screenshots of the graphic user interfaces for defining the inputs used in developing the (a) noise map and the (b) façade map of the study area

as well (Gilani and Mir 2021). The survey was conducted from 1 October 2020 to 7 December 2020 (9 weeks).

\section{Statistical analysis}

Descriptive analysis was run for the categorical variables using the chi-square test. The Pearson correlation coefficient was obtained for the verbal and numerical annoyance rating scales. Significant predictors of traffic noise annoyance were obtained using multiple logistic regression, and the odds ratio was calculated for all the significant variables. A 95\% level of significance was chosen for the study, which means a $p$-value
$<0.05$ was considered to be significant. All the analysis was performed using SPSS V25.0 for Windows (SPSS, Inc, Chicago, IL).

\section{Results}

\section{Evaluation of the response sheets}

The response sheets were evaluated manually by the authors based on the attention question criterion. We found that 5 response sheets failed to meet the desired criterion and hence

Fig. 5 Sample size calculation curves based on power, significance level, and effect size used in the study

$z$ tests - Logistic regression

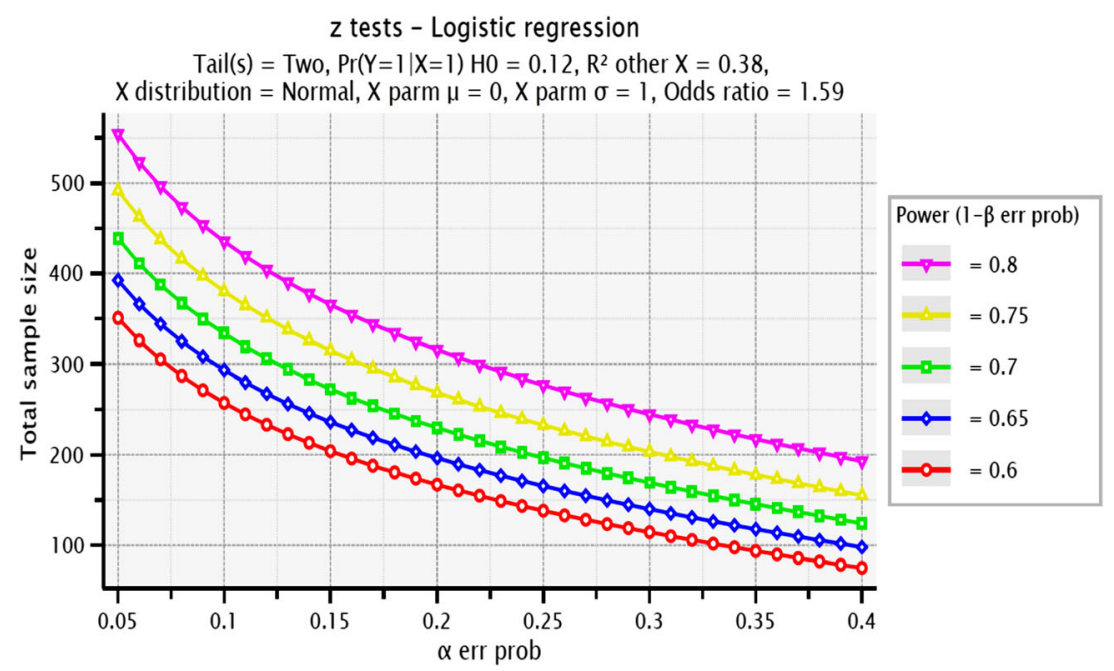


Table 4 Statements about various reported health effects used in the questionnaire

\begin{tabular}{|c|c|c|c|}
\hline $\begin{array}{l}\text { Statement } \\
\text { no. }\end{array}$ & Wording & Response & Reference \\
\hline 1 & RTN can cause heart disease & $\begin{array}{l}\text { 1, not at all; } 2 \text {, slightly; } 3 \text {, moderately; } \\
4 \text {, to a good extent; } 5 \text {, completely agree }\end{array}$ & Banerjee et al. (2014) \\
\hline 2 & RTN can cause diabetes & $\begin{array}{l}\text { 1, not at all; } 2 \text {, slightly; } 3 \text {, moderately; } \\
4 \text {, to a good extent; } 5 \text {, completely agree }\end{array}$ & Sorensen et al. (Mette et al. 2013) \\
\hline 3 & RTN can cause hypertension & $\begin{array}{l}1 \text {, not at all; } 2 \text {, slightly; } 3 \text {, moderately; } \\
4 \text {, to a good extent; } 5 \text {, completely agree }\end{array}$ & Bodin et al. (2009) \\
\hline 4 & RTN can cause stroke & $\begin{array}{l}1 \text {, not at all; } 2 \text {, slightly; } 3 \text {, moderately; } \\
4 \text {, to a good extent; } 5 \text {, completely agree }\end{array}$ & Sorensen et al. (2011) \\
\hline 5 & RTN can reduce your working efficiency & $\begin{array}{l}\text { 1, not at all; } 2 \text {, slightly; } 3 \text {, moderately; } \\
4 \text {, to a good extent; } 5 \text {, completely agree }\end{array}$ & Zaheeruddin and Garima (2006) \\
\hline 6 & RTN can cause stress & $\begin{array}{l}1, \text { not at all; } 2 \text {, slightly; } 3 \text {, moderately; } \\
4 \text {, to a good extent; } 5 \text {, completely agree }\end{array}$ & Jensen et al. (2018) \\
\hline
\end{tabular}

$R T N$ road traffic noise

were separated from the rest of the response sheets. However, we further evaluated these 5 response sheets to prevent any bias and found that even most portion of the questionnaire was left unanswered by the respondents, thereby further supporting our decision to exclude them from the analysis.

\section{Noise level assessment}

At all the selected 41 measurement points, traffic noise was found to be well above the upper safe limit prescribed by both WHO and CPCB for daytime as well as night-time. The average noise level in the noisy area was $12 \mathrm{~dB}(\mathrm{~A})$ higher as compared to that of quiet areas. Srinagar City due to its large size was subdivided into zones for developing a noise map. In this study, a noise-sensitive area with a super-speciality hospital serving the majority of the districts in the Kashmir division was selected. The area also has a residential zone in its immediate vicinity. A noise map was developed for the study area based on the modelled day-night noise level $\left(\mathrm{L}_{\mathrm{DN}}\right)$ index. The noise map shown in Figure 6 depicts that the area suffers from serious noise pollution. The map clearly shows that the noise levels around the residential and super-speciality hospital premises are above $57 \mathrm{~dB}(\mathrm{~A})$ with maximum levels going above $75 \mathrm{~dB}(\mathrm{~A})$. The façade map of the study area shown in Figure 7 shows that the noise levels reaching the facades of most of the residential buildings exceed $60 \mathrm{~dB}(\mathrm{~A})$ (light red to dark red colour) with some of the houses located close to the congestion points experiencing noise levels greater than 70 $\mathrm{dB}(\mathrm{A})$ (deep blue colour).

\section{Demographic characteristics and traffic noise annoyance assessment}

A total of 565 respondents were selected after screening the response sheets as shown in Table 5. Incomplete response sheets or sheets which failed to satisfy the criterion concerning attention questions were left out. The final sample comprised $48.5 \%$ males and $51.5 \%$ females. Of the respondents, $82 \%$ belonged to noisy areas and $18 \%$ belonged to quiet areas. The respondents, divided in 4 age groups: $(<20)$ years, $(20$ to 40 ) years, (40 to 60) years, and ( $>60)$ years represented $13.5 \%, 25.5 \%, 39.5 \%$, and $21.5 \%$ of the sample size respectively The residence period was divided into three categories: ( 1 to 2 ) years, ( 2 to 5 ) years, and (> 5) years. It comprised of $26.9 \%, 31.3 \%$, and $41.8 \%$ of the sample size respectively. Based on educational qualification, respondents were divided into four categories: (up to high school), (graduation), (master's), and (higher). The total composition consisted of $19.1 \%$, $48.1 \%, 25.1 \%$, and $7.6 \%$ respectively. Of the respondents, $68.3 \%$ were not suffering from any chronic disease. Perception of traffic noise at home was reported by $85 \%$ of the respondents, and nearly $64 \%$ of the respondents considered traffic noise to be extremely noisy.

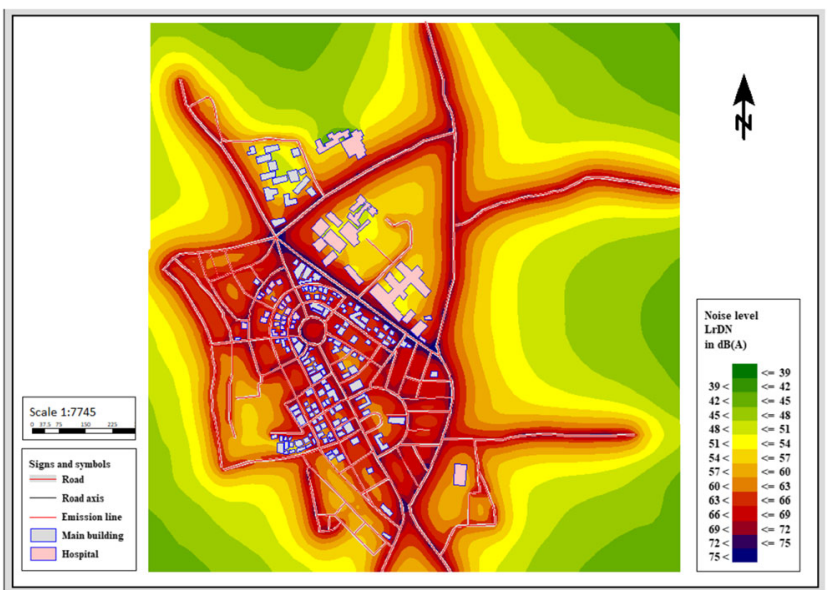

Fig. 6 Noise map of the study area developed using the SoundPLAN software 


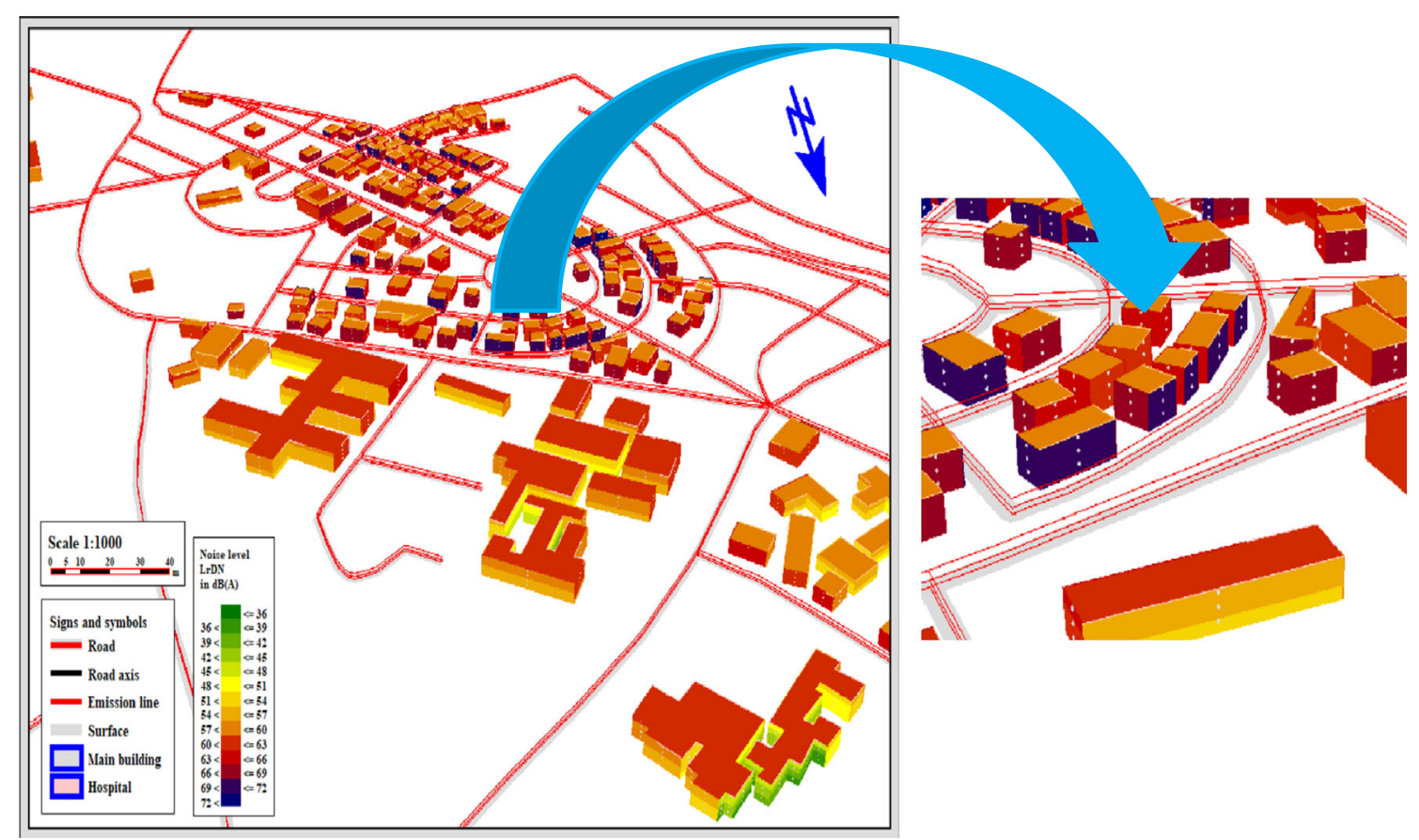

Fig. 7 Façade map of the study area developed using the SoundPLAN software

\section{Noise annoyance survey}

Traffic noise related annoyance was reported by nearly $84 \%$ of the respondents. About 58.1\%, 59.3\%, 66.4\%, and 66\% reported feeling annoyed due to traffic noise while studying, concentrating, resting, and talking respectively. Nearly $62.3 \%$ of the respondents reported poor sleep quality due to traffic noise. Associations were observed between living in noisy areas and feeling annoyed due to traffic noise $(p<0.001)$ and feeling annoyed due to the interference of traffic noise in activities like studies $(\mathrm{p}<0.001)$, concentrating $(\mathrm{p}<$ $0.001)$, and resting $(\mathrm{p}<0.001)$. Talking and reporting of sleep quality were not associated with the acoustical classification of the area, as shown in Table 6. Pearson correlation between the verbal and numerical annoyance scale revealed a high degree of correlation $(r=0.955, p<0.001)$. Depending upon the annoyance scales, we classified the respondents as not annoyed and highly annoyed. Respondents who replied very or extremely on the verbal scale or those who rated their annoyance level $>6$ were considered to be highly annoyed. The classification cut-offs were chosen based on another study in which both scales were used ( $\mathrm{Li}$ et al. 2008). The distribution of the respondents based on the two annoyance scales is shown in Figures 8 and 9 respectively.

\section{Dose-effect curves}

Based on the questionnaire survey and the exposure levels of the residents obtained through the façade map of the study area, the dose-effect curve was plotted. The dose used was the traffic noise level, $\mathrm{L}_{\mathrm{DN}}$, while the response was the percentage of highly annoyed residents at the given level of exposure. Of the data obtained, $75 \%$ was used for developing the curves while the remaining $25 \%$ was used for validating the model. The fitted curve is given by Equation 2 and is depicted in Figure 10.

$\% H A=2.91+\left\{\frac{76.1}{1+10^{\left(9.81-0.16 \times L_{D N}\right)}}\right\}$

The results from the validity test of the model are shown in Table 7. It was found that the results were within a range of (1.59-8.79) from the actual values. The model showed higher deviation from the actual values at higher noise levels while the model showed smaller deviations at lower noise levels.

\section{Assessment of level agreement and awareness level about traffic noise-related health effects}

Table 8 shows the respondents' agreement level about various serious health impacts related to RTN. The results from the table reveal that more than half of the respondents disagreed with the statements made, except for stress. Stress was also the only known negative outcome in which the average MAIS score crossed the cut-off value while work efficiency was close to the cut-off value of 2 . For heart attack, diabetes, hypertension, and stroke, the values of MAIS were 1.54, 1.44, 1.59, and 1.48 respectively as shown in Figure 11. The differences in the responses based on gender and level of education were also determined. Table 9 illustrates the differences in the 
Table 5 Gender, age, marital status, residence period, education level, chronic disease, perception of traffic noise, and acoustic quality reported by respondents in relation to the type of area

\begin{tabular}{|c|c|c|c|c|}
\hline $\begin{array}{l}\text { Sociodemographic-related } \\
\text { characteristics }\end{array}$ & $\begin{array}{l}\text { Quiet area } \\
(\mathrm{n}=102)\end{array}$ & $\begin{array}{l}\text { Noisy area } \\
(\mathrm{n}=463)\end{array}$ & $\begin{array}{l}\text { Total } \\
\text { population }(\%)\end{array}$ & $\mathrm{p}^{*}$-value \\
\hline Gender & & & & $<0.001$ \\
\hline Male & 78 & 196 & 48.5 & \\
\hline Female & 24 & 267 & 51.5 & \\
\hline Age (in years) & & & & $<0.001$ \\
\hline$<20$ & 70 & 6 & 13.5 & \\
\hline 20 to 40 & 32 & 112 & 25.5 & \\
\hline 40 to 60 & 0 & 223 & 39.5 & \\
\hline$>60$ & 0 & 122 & 21.5 & \\
\hline Marital status & & & & 0.403 \\
\hline Unmarried & 38 & 142 & 31.9 & \\
\hline Married & 48 & 233 & 49.7 & \\
\hline Widowed/divorced & 16 & 88 & 18.4 & \\
\hline Residence period (in years) & & & & $<0.001$ \\
\hline 1 to 2 & 52 & 100 & 26.9 & \\
\hline 2 to 5 & 23 & 154 & 31.3 & \\
\hline$>5$ & 27 & 209 & 41.8 & \\
\hline Education level & & & & $<0.001$ \\
\hline Up to high school & 61 & 47 & 19.1 & \\
\hline Graduation & 13 & 259 & 48.1 & \\
\hline Master's & 21 & 121 & 25.1 & \\
\hline Higher & 7 & 36 & 7.6 & \\
\hline Chronic disease & & & & 0.586 \\
\hline No & 72 & 314 & 68.3 & \\
\hline Yes & 30 & 149 & 31.7 & \\
\hline Perception of noise at home & & & & $<0.001$ \\
\hline No & 85 & 0 & 15 & \\
\hline Yes & 17 & 463 & 85 & \\
\hline Noise quality at home & & & & $<0.001$ \\
\hline Quiet & 81 & 0 & 14.3 & \\
\hline Moderately noisy & 21 & 104 & 22.1 & \\
\hline Extremely noisy & 0 & 359 & 63.5 & \\
\hline
\end{tabular}

* Chi-square test

level of agreements based on gender. There was no significant association in the level of agreement between males and females for the first statement regarding heart attack $(\mathrm{p}>0.05)$. For the second statement regarding diabetes, there was a statistically significant association between the level of agreement and gender, $\chi^{2}(4)=56.96, p<0.001$. The association was moderate, Cramer's V $=0.309$ (Jacob Cohen 1988). For the third statement regarding hypertension, there was a statistically significant association between the level of agreement and gender, $\chi^{2}(4)=24.22, p<0.001$. The association was small, Cramer's V $=0.207$. There was no significant association in the level of agreement and gender for the fourth statement regarding stroke $(\mathrm{p}>0.05)$. For the fifth statement regarding work efficiency, there was a statistically significant association between the level of agreement and gender, $\chi^{2}$ (4)
$=40.67, \mathrm{p}<0.001$. The association was small, Cramer's $\mathrm{V}=$ 0.268 . There was no significant association between the level of agreement and gender for the sixth statement regarding stress $(\mathrm{p}>0.05)$.

Table 10 shows the association between the level of agreements and the level of education. There was a significant association between the first statement regarding heart attack and educational level, $\chi^{2}(12)=32.41, p=0.001$. The association was small, though, Cramer's $\mathrm{V}=0.135$. There was a significant association between the second statement regarding diabetes and educational level, $\chi^{2}(12)=213.84, p<$ 0.001 . The association was moderate, Cramer's V $=0.328$. There was a significant association between the third statement regarding hypertension and educational level, $\chi^{2}$ (12) $=36.94, \mathrm{p}<0.001$. The association was small, Cramer's V 
Table 6 Distribution of residents according to annoyance and parameters related to annoyance as a function of road traffic noise

\begin{tabular}{|c|c|c|c|c|}
\hline Parameters & $\begin{array}{l}\text { Quiet area } \\
(\mathrm{n}=102)\end{array}$ & $\begin{array}{l}\text { Noisy area } \\
(\mathrm{n}=463)\end{array}$ & $\begin{array}{l}\text { Total } \\
\text { population }(\%)\end{array}$ & $\mathrm{p}^{*}$-value \\
\hline Annoyance due to traffic noise & & & & $<0.001$ \\
\hline No & 77 & 14 & 16.1 & \\
\hline Yes & 25 & 449 & 83.9 & \\
\hline \multicolumn{5}{|l|}{ Annoyance during activities } \\
\hline Studies & & & & $<0.001$ \\
\hline No & 40 & 197 & 41.9 & \\
\hline Yes & 102 & 226 & 58.1 & \\
\hline Concentration & & & & 0.001 \\
\hline No & 57 & 173 & 40.7 & \\
\hline Yes & 45 & 290 & 59.3 & \\
\hline Resting & & & & 0.044 \\
\hline No & 43 & 147 & 33.6 & \\
\hline Yes & 59 & 316 & 66.4 & \\
\hline Talking & & & & 0.054 \\
\hline No & 43 & 149 & 33.9 & \\
\hline Yes & 59 & 314 & 66.1 & \\
\hline Sleep quality & & & & 0.423 \\
\hline Excellent & 42 & 171 & 37.7 & \\
\hline Poor & 60 & 292 & 62.3 & \\
\hline
\end{tabular}

${ }^{*}$ Chi-square test
$=0.145$. There was a significant association between the fourth statement regarding stroke and educational level, $\chi^{2}$ $(12)=33.09, p=0.001$. The association was small, Cramer's V $=0.142$. There was a significant association between the fifth statement regarding work efficiency and educational level, $\chi^{2}(12)=135.25, p<0.001$. The association was small, Cramer's V $=0.282$. There was a significant association between the sixth statement regarding stress and educational level, $\chi^{2}(12)=108.91, p<0.001$. The association was small, Cramer's V $=0.253$.

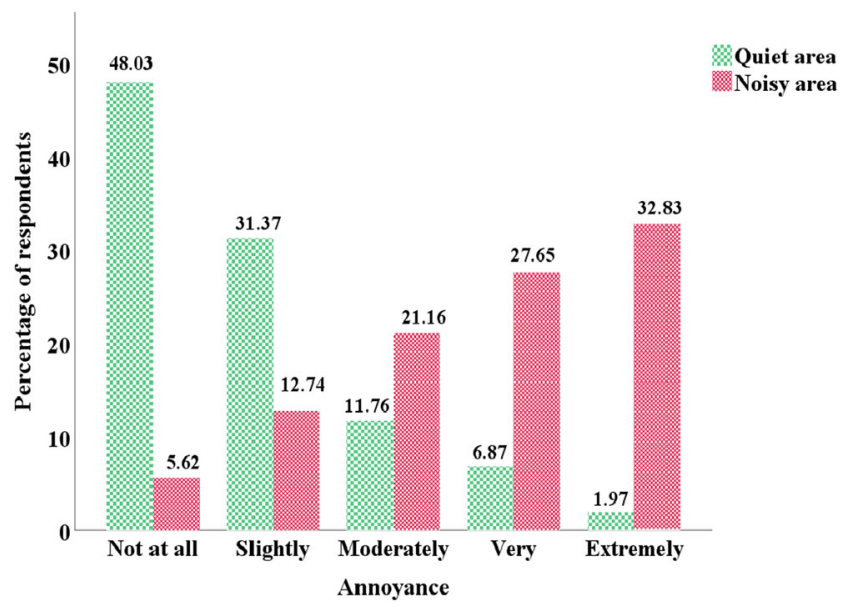

Fig. 8 Comparison of the number of respondents for annoyance level using the verbal scale for noisy and quiet areas

\section{The result from multivariate logistic regression}

To keep the model simple and avoid overfitting, two models were developed based on the two annoyance scales. The results are shown in Table 11. After adjusting for sensitivity, residence period, gender, sleep quality, and noise perception at home, the models depicted that living in the noisy area was significantly associated with a high risk of being highly annoyed $(\mathrm{OR}=4.06, \mathrm{p}<0.001$ in model $1 ; \mathrm{OR}=3.93$, $\mathrm{p}<$ 0.001 in model 2). Concerning sensitivity, respondents who were classified as sensitive were having a 4 times more risk for being highly annoyed as compared to those who were not sensitive $(\mathrm{OR}=3.98, \mathrm{p}<0.001$ in model 1 ; $\mathrm{OR}=3.92, \mathrm{p}<$ 0.001 in model 2). Gender was not a significant factor for annoyance levels reported using both scales. Self-reported sleep quality was a significant predictor for noise-induced annoyance. Respondents with poor sleep quality were having a 4 times more risk of being highly annoyed as compared to those reporting excellent quality $(\mathrm{OR}=3.94, \mathrm{p}<0.001$ in model 1; OR $=3.91, \mathrm{p}<0.001$ in model 2). Perception of traffic noise at home was also a significant predictor of annoyance. Respondents who perceived traffic noise at home were having a 3.15 times higher risk as compared to those who did not perceive noise at home $(\mathrm{OR}=3.15, \mathrm{p}<0.001$ in model 1 ; $\mathrm{OR}=3.13, \mathrm{p}<0.001$ in model 2 ). 
Fig. 9 Comparison of the respondents based on annoyance level using the numerical scale for noisy and quiet areas

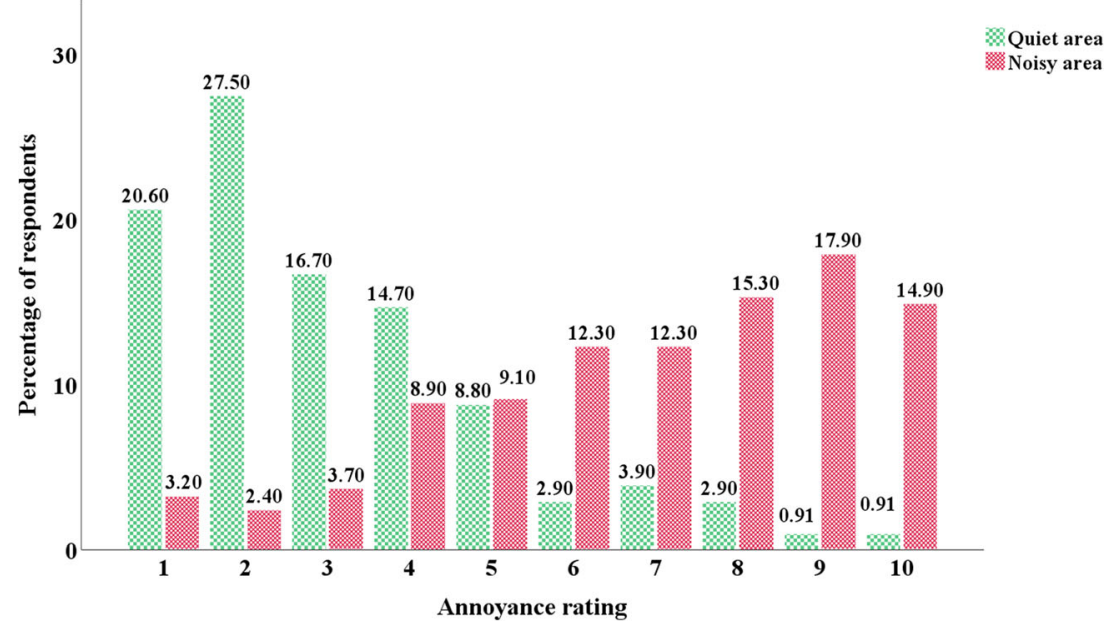

\section{Discussions}

The impacts of the road traffic noise in urban areas have been a matter of study not only because of the number of motor vehicles plying on roads but also due to high levels of annoyance response that road traffic noise can evoke, thereby causing a decrease in the quality of life in urban areas (Babisch et al. 2009; Jones 2010; Lekaviciute and Argalasova Sobotova 2013). Research has shown that annoyance is more related to road traffic as compared to that with rail or air traffic (Basner et al. 2011). The noise map of the study area revealed high noise levels, which are represented by darker colours (dark blue) and can reach above $75 \mathrm{~dB}(\mathrm{~A})$. One of the possible reasons for such high noise levels in the study area during both daytime and night-time is the presence of tertiary care and super-speciality hospital. Both these facilities are located along roads that witness a continuous movement of private vehicles, commercial vehicles, and ambulances during both daytime and night-time. This continuous movement is characterized by frequent honking, which leads to high noise

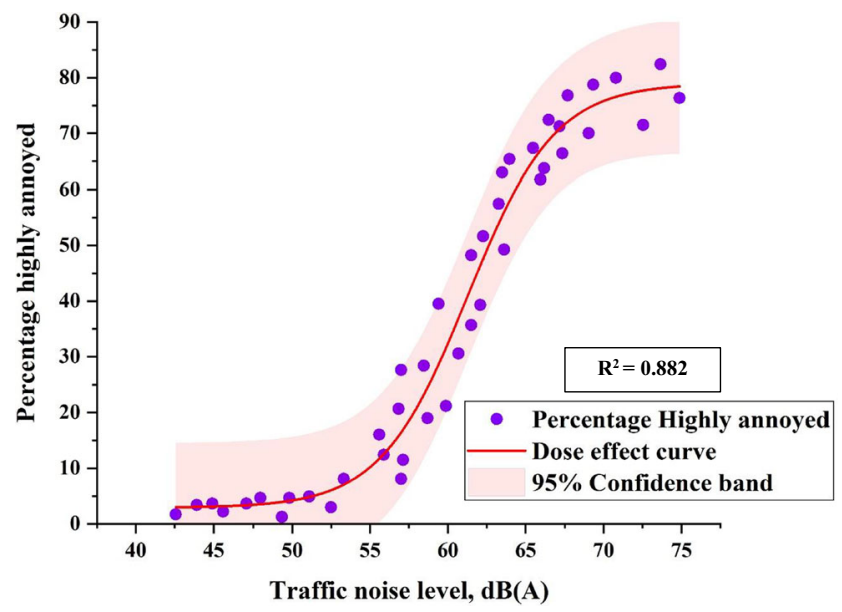

Fig. 10 Dose-effect curve for the percentage of highly annoyed residents along with $95 \%$ confidence band levels in the study area. The honking by the drivers is further exacerbated due to frequent stops made by the passenger vehicles at places other than the designated stops. The contribution of honking in elevating the noise levels in the Indian context has been found in other studies as well (Thakre et al. 2020). Also, the current COVID-19 pandemic has resulted in higher vehicular movement in the areas adjacent to health centres and tertiary care hospitals. This might have also resulted in higher noise levels.

Noise mapping helps in better visualization of the noise dispersion and levels at all points. This enables better

Table 7 Comparison between the predicted and actual percentage of highly annoyed population

\begin{tabular}{llll}
\hline $\begin{array}{l}\text { Traffic noise } \\
\text { level, dB(A) }\end{array}$ & $\begin{array}{l}\text { Predicted (\%) } \\
\text { highly annoyed }\end{array}$ & $\begin{array}{l}\text { Actual (\%) highly } \\
\text { annoyed }\end{array}$ & Difference \\
\hline 51.32 & 4.82 & 3.23 & 1.59 \\
52.36 & 5.68 & 3.77 & 1.91 \\
54.65 & 9.06 & 6.90 & 2.16 \\
57.39 & 17.70 & 15.49 & 2.21 \\
58.69 & 24.24 & 19.12 & 5.12 \\
60.29 & 34.30 & 29.36 & 4.94 \\
61.33 & 41.52 & 35.26 & 6.26 \\
62.32 & 48.36 & 45.29 & 3.07 \\
62.56 & 49.97 & 43.26 & 6.71 \\
63.35 & 54.99 & 49.36 & 5.63 \\
64.98 & 63.64 & 57.26 & 6.38 \\
66.31 & 68.80 & 64.15 & 4.65 \\
67.19 & 71.34 & 66.23 & 5.11 \\
69.33 & 75.32 & 68.31 & 7.01 \\
69.88 & 75.97 & 67.18 & 8.79 \\
70.16 & 76.26 & 69.36 & 6.90 \\
72.32 & 77.74 & 70.35 & 7.39 \\
73.26 & 78.11 & 72.25 & 5.86 \\
\hline & & & \\
\hline
\end{tabular}


Table 8 Response of the participants about the statements regarding the effects of traffic noise $(\mathrm{N}=565)$

\begin{tabular}{|c|c|c|}
\hline Statement & $\mathrm{N}$ & Percentage $(\%)$ \\
\hline \multicolumn{3}{|c|}{ RTN can cause heart attack } \\
\hline Not at all & 362 & 64.07 \\
\hline Slightly & 131 & 23.19 \\
\hline Moderately & 46 & 8.14 \\
\hline To a good extent & 20 & 3.53 \\
\hline Completely & 6 & 1.06 \\
\hline \multicolumn{3}{|c|}{ RTN can cause diabetes } \\
\hline Not at all & 382 & 67.61 \\
\hline Slightly & 128 & 22.65 \\
\hline Moderately & 45 & 7.96 \\
\hline To a good extent & 7 & 1.24 \\
\hline Completely & 3 & 0.53 \\
\hline \multicolumn{3}{|c|}{ RTN can cause hypertension } \\
\hline Not at all & 359 & 63.54 \\
\hline Slightly & 131 & 23.18 \\
\hline Moderately & 36 & 6.37 \\
\hline To a good extent & 26 & 4.6 \\
\hline Completely & 13 & 2.3 \\
\hline \multicolumn{3}{|c|}{ RTN can cause stroke } \\
\hline Not at all & 373 & 66.02 \\
\hline Slightly & 141 & 24.95 \\
\hline Moderately & 32 & 5.66 \\
\hline To a good extent & 11 & 1.95 \\
\hline Completely & 8 & 1.42 \\
\hline \multicolumn{3}{|c|}{ RTN can reduce your working efficiency } \\
\hline Not at all & 286 & 50.62 \\
\hline Slightly & 142 & 25.13 \\
\hline Moderately & 65 & 11.5 \\
\hline To a good extent & 41 & 7.26 \\
\hline Completely & 31 & 5.49 \\
\hline \multicolumn{3}{|c|}{ RTN can cause stress } \\
\hline Not at all & 136 & 24.07 \\
\hline Slightly & 96 & 16.99 \\
\hline Moderately & 86 & 15.22 \\
\hline To a good extent & 125 & 22.12 \\
\hline Completely & 122 & 21.59 \\
\hline
\end{tabular}

$R T N$ road traffic noise

understanding of the problem which cannot be achieved by traditional measurement methods. This feature makes noise mapping a better tool for the improvement and management of the urban acoustic environment. The utilization of the standard noise prediction model (TNM 2.5) in the present study was based on a previous study conducted for Indian conditions and was further validated using statistical results. India is a developing country and has been experiencing tremendous growth in the vehicle population. Registered vehicle growth
Table 9 Comparison of responses to the health statements based on gender using chi-square test

\begin{tabular}{|c|c|c|c|c|}
\hline \multirow[t]{2}{*}{ Response } & $\begin{array}{l}\text { Male } \\
(n=274)\end{array}$ & $\begin{array}{l}\text { Female } \\
(\mathrm{n}=291)\end{array}$ & \multirow[t]{2}{*}{$x^{2}$} & \multirow[t]{2}{*}{ p-value } \\
\hline & $\%$ & $\%$ & & \\
\hline
\end{tabular}

$\begin{array}{lllllll}\text { S1: Road traffic noise can lead to heart attack } \\ \text { Not at all } & 168 & 61.31 & 194 & 66.67 & 7.11 & 0.130 \\ \text { Slightly } & 69 & 25.18 & 62 & 21.31 & & \\ \text { Moderately } & 28 & 10.22 & 18 & 6.19 & & \\ \text { To a good extent } & 6 & 2.19 & 14 & 4.81 & & \\ \text { Completely } & 3 & 1.09 & 3 & 1.03 & & \end{array}$

S2: Road traffic noise can lead to diabetes

$\begin{array}{lllllll}\text { Not at all } & 218 & 79.56 & 164 & 56.36 & 56.96 & <0.001 \\ \text { Slightly } & 26 & 9.48 & 102 & 35.05 & & \\ \text { Moderately } & 26 & 9.48 & 19 & 6.53 & & \\ \text { To a good extent } & 3 & 1.09 & 4 & 1.37 & & \\ \text { Completely } & 1 & 0.36 & 2 & 0.69 & & \end{array}$

S3: Road traffic noise can cause hypertension

$\begin{array}{lllllll}\text { Not at all } & 162 & 59.12 & 197 & 67.69 & 24.22 & <0.001 \\ \text { Slightly } & 86 & 31.39 & 45 & 15.46 & & \\ \text { Moderately } & 15 & 5.47 & 21 & 7.22 & & \\ \text { To a good extent } & 7 & 2.55 & 19 & 6.53 & & \\ \text { Completely } & 4 & 1.46 & 9 & 3.09 & & \end{array}$

S4: Road traffic noise can cause stroke

$\begin{array}{lllllll}\text { Not at all } & 181 & 66.06 & 192 & 65.97 & 6.27 & 0.180 \\ \text { Slightly } & 62 & 22.63 & 79 & 27.15 & & \\ \text { Moderately } & 17 & 6.20 & 15 & 5.15 & & \\ \text { To a good extent } & 8 & 2.92 & 3 & 1.03 & & \\ \text { Completely } & 6 & 2.19 & 2 & 0.69 & & \end{array}$

S5: Road traffic noise can reduce the working efficiency

$\begin{array}{lllllll}\text { Not at all } & 109 & 39.78 & 177 & 60.82 & 40.67 & <0.001 \\ \text { Slightly } & 73 & 26.64 & 69 & 23.71 & & \\ \text { Moderately } & 36 & 13.14 & 29 & 9.96 & & \\ \text { To a good extent } & 29 & 10.58 & 12 & 4.12 & & \\ \text { Completely } & 27 & 9.85 & 4 & 1.37 & & \end{array}$

S6: Road traffic noise can cause stress

\begin{tabular}{lllllll} 
Not at all & 66 & 24.09 & 70 & 24.05 & 4.41 & 0.353 \\
Slightly & 41 & 14.96 & 55 & 18.90 & & \\
Moderately & 45 & 16.42 & 41 & 14.09 & & \\
To a good extent & 68 & 24.82 & 57 & 19.59 & & \\
Completely & 54 & 19.71 & 68 & 23.37 & & \\
\hline
\end{tabular}

has seen a growth rate of $9.9 \%$ between 2001 and 2011 (Ministry of Road Transport and Highways 2011). However, such a high growth rate needs to be complemented with requisite infrastructure, which the developing countries including India haven ' $t$ been able to provide due to limited resources. This has resulted in an additional burden over the already burdened infrastructure (Pucher et al. 2004). Such an imbalance between demand and supply will further increase noise 


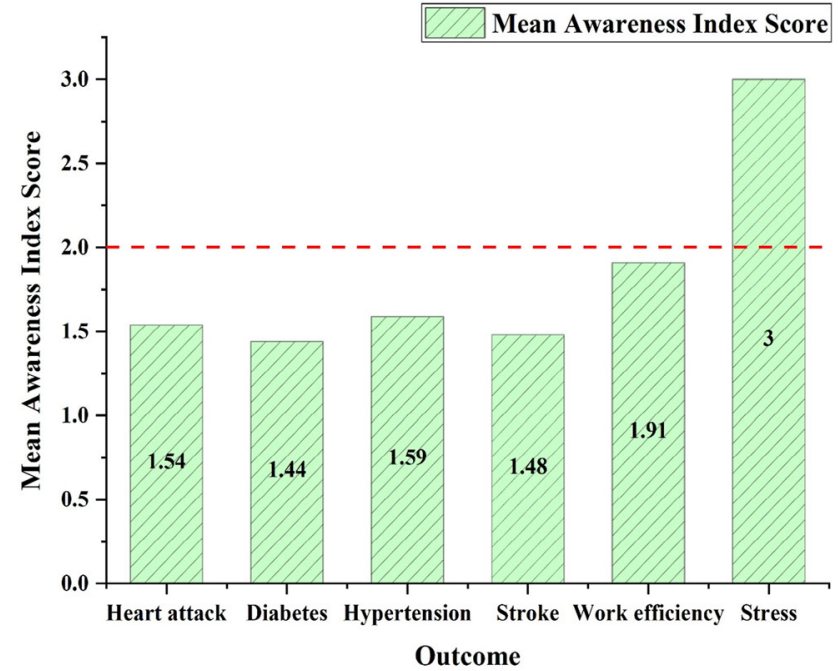

Fig. 11 Mean awareness index score for the health effects due to traffic noises

levels, and thus, more severe health impacts due to traffic noise can occur.

The reporting of perception of traffic noise by a high percentage (85\%) of respondents and feeling annoyed due to the interference with daily life activities suggest that traffic noise is acting as an environmental stressor in the study area. This is a significant finding as the area comes under the silence zone category, and as such, measures should be taken to bring the noise levels within permissible limits. A study conducted in Brazil reported similar percentages of annoyed and sleepdisturbed respondents (Paiva et al. 2019). While evaluating the awareness level about various established health effects of traffic noise, it was found that the majority of the population was having little or no awareness, except for stress. The majority of the respondents reported disagreement with the statements presented in the questionnaire. This is an important observation given the majority (65\%) of the respondents were in the age group of 20 to 60 years. Adding to this worrying factor is the high literacy rate, which means that despite nearly $81 \%$ of respondents being educated (having at least a bachelor's degree), respondents have little or no awareness about the adverse health effects that can be caused by traffic noise. There are a small percentage of highly educated individuals who agreed with the statements of the questionnaire and the majority of them reported disagreement. This reveals the lack of awareness among the masses and the lack of efforts from the regulating authorities. The reporting of disagreements concerning the established health effects caused by traffic noise also indicates that residents of the area are not going to adopt suitable measures or modify their residential places to reduce the noise exposure. This can result in a substantial increase in the burden of disease due to environmental noise exposure in the study area. We hypothesize that the reason for underestimating environmental noise in general and traffic noise, in particular, is the time factor. The negative effects due to traffic noise usually occur over a significant period as compared to the similar effects caused due to other pollutants like air pollution. However, higher agreement with the stress statement can be attributed to the loss of control over the personal environment that exposed people may feel. Residential areas are meant for resting, spending time with family, and other personal activities. Similarly, workplaces require a serene environment for proper functioning and improving output. The interference caused by traffic noise hinders the achievement of the desired goals, and as such, the individuals feel annoyed or stressed.

Multivariate logistic regression revealed a high risk for people living in noisy areas as compared to those living in quiet areas. This can be the result of perceived helplessness in achieving the desired control over the surroundings, especially at home or at workplaces. Interference of traffic noise in daily life activities also contributes towards annoyance. The findings depict a higher risk of suffering from poor health. This is because WHO defines health as a state of complete physical, social, and mental wellbeing while annoyance refers to feelings such as irritation, stress, anxiety, anger, and frustration, all of which favour the development of health issues (Dratva et al. 2010; Ndrepepa and Twardella 2011; WHO 2011). The association between living in a noisy area and interference in activities is an important outcome as the same has been reported in the literature and confirmed by WHO (Babisch 2005; WHO 2011). The effect of the residence period was not significant in both models. This may occur due to the acceptance or adaptation to the surrounding environment by the residents. The results are further supported by another study carried out in West Bengal, India (Banerjee 2013). Gender was not found to be a significant factor in both models. There has been heterogeneity in the results concerning gender and annoyance. Some studies have reported significant effects (Dratva et al. 2010; Banerjee 2013) while others have reported no effect (Park et al. 2018a; Sieber et al. 2018; Beheshti et al. 2019). Respondents who were sensitive to noise were having nearly 4 times higher risk as compared to non-sensitive respondents. Generally, sensitive people have higher expectations attached with their residential or workplaces, but the unavailability of such ideal conditions can raise their level of anger, stress, irritation, or frustration, which means they are more prone to reporting higher annoyance levels. Similar results are also reported in other studies (Vastfjall 2002; Fyhri and Klaeboe 2009; Ryu and Jeon 2011). The models report a significant association between higher annoyance levels and poor sleep quality. A study conducted in the Netherlands reported nearly the same scores on sleep disturbance caused due to traffic noise and neighbourhood noise, which means that sleep disturbance is not related to the level of noise or source of noise (van den Berg et al. 2014). The study reported a stronger association of 
Table 10 Comparison of responses to the health statements based on education level using chi-square test

\begin{tabular}{|c|c|c|c|c|c|c|}
\hline Education & $\begin{array}{l}\text { High school } \\
(\mathrm{n}=108)\end{array}$ & $\begin{array}{l}\text { Bachelor's } \\
(\mathrm{n}=272)\end{array}$ & $\begin{array}{l}\text { Master's } \\
(\mathrm{n}=142)\end{array}$ & $\begin{array}{l}\text { Higher } \\
(\mathrm{n}=43)\end{array}$ & $x^{2}$ & $\mathrm{p}$-value \\
\hline Response & $\%$ & $\%$ & $\%$ & $\%$ & & \\
\hline
\end{tabular}

S1: Road traffic noise can lead to heart attack

$\begin{array}{lllllllll}\text { Not at all } & 57 & 52.8 & 165 & 60.7 & 106 & 74.6 & 34 & 79.1 \\ \text { Slightly } & 37 & 34.3 & 64 & 23.5 & 26 & 18.3 & 4 & 9.3 \\ \text { Moderately } & 12 & 11.1 & 26 & 9.6 & 6 & 4.2 & 2 & 4.7 \\ \text { Good extent } & 1 & 0.9 & 15 & 5.5 & 2 & 1.4 & 2 & 4.7 \\ \text { Completely } & 1 & 0.9 & 2 & 0.7 & 2 & 1.4 & 1 & 2.3\end{array}$

S2: Road traffic noise can lead to diabetes

$\begin{array}{lllllllllll}\text { Not at all } & 78 & 72.2 & 222 & 81.6 & 61 & 43.0 & 21 & 48.8 & 213.84 & <0.001 \\ \text { Slightly } & 18 & 16.7 & 40 & 14.7 & 155 & 38.7 & 15 & 34.9 & & \\ \text { Moderately } & 12 & 11.1 & 10 & 3.7 & 19 & 13.4 & 4 & 9.3 & \\ \text { Good extent } & 0 & 0 & 0 & 0 & 6 & 4.2 & 1 & 2.3 & \\ \text { Completely } & 0 & 0 & 0 & 0 & 1 & 0.7 & 2 & 4.7 & \end{array}$

S3: Road traffic noise can cause hypertension

\begin{tabular}{|c|c|c|c|c|c|c|c|c|c|c|}
\hline Not at all & 66 & 61.1 & 183 & 67.3 & 84 & 59.2 & 26 & 60.5 & \multirow[t]{2}{*}{36.94} & \multirow[t]{2}{*}{$<0.001$} \\
\hline Slightly & 22 & 20.4 & 71 & 26.1 & 30 & 21.1 & 8 & 18.6 & & \\
\hline Moderately & 8 & 7.4 & 11 & 4.0 & 14 & 9.9 & 3 & 7.0 & & \\
\hline Good extent & 9 & 8.3 & 7 & 2.6 & 5 & 3.5 & 5 & 11.6 & & \\
\hline Completely & 3 & 2.8 & 0 & 0 & 9 & 6.3 & 1 & 2.3 & & \\
\hline \multicolumn{11}{|c|}{ 4: Road traffic noise can cause stroke } \\
\hline Not at all & 67 & 62.0 & 182 & 66.9 & 96 & 67.6 & 28 & 65.1 & \multirow[t]{5}{*}{33.09} & \multirow[t]{5}{*}{0.001} \\
\hline Slightly & 27 & 25.0 & 73 & 26.8 & 36 & 25.4 & 5 & 11.6 & & \\
\hline Moderately & 8 & 7.4 & 9 & 3.3 & 8 & 5.6 & 7 & 16.3 & & \\
\hline Good extent & 5 & 4.6 & 1 & 0.4 & 2 & 1.4 & 3 & 7.0 & & \\
\hline Completely & 1 & 0.9 & 7 & 2.6 & 0 & 0 & 0 & 0 & & \\
\hline \multicolumn{11}{|c|}{ 5: Road traffic noise can reduce the working efficiency } \\
\hline Not at all & 62 & 57.4 & 175 & 64.3 & 23 & 16.2 & 26 & 60.5 & \multirow[t]{5}{*}{135.253} & \multirow[t]{5}{*}{$<0.001$} \\
\hline Slightly & 21 & 19.4 & 71 & 26.1 & 42 & 29.6 & 8 & 18.6 & & \\
\hline Moderately & 13 & 12.0 & 18 & 6.6 & 29 & 20.4 & 5 & 11.6 & & \\
\hline Good extent & 7 & 6.5 & 6 & 2.2 & 26 & 18.3 & 2 & 4.7 & & \\
\hline Completely & 5 & 4.6 & 2 & 0.7 & 22 & 15.5 & 2 & 4.7 & & \\
\hline \multicolumn{11}{|c|}{ 6: Road traffic noise can cause stress } \\
\hline Not at all & 36 & 33.3 & 62 & 22.8 & 21 & 14.8 & 17 & 39.5 & \multirow[t]{5}{*}{108.91} & \multirow[t]{5}{*}{$<0.001$} \\
\hline Slightly & 24 & 22.2 & 35 & 12.9 & 21 & 14.8 & 16 & 37.2 & & \\
\hline Moderately & 21 & 19.4 & 29 & 10.7 & 28 & 19.7 & 8 & 18.6 & & \\
\hline Good extent & 19 & 17.6 & 50 & 14.7 & 54 & 38.0 & 2 & 4.7 & & \\
\hline Completely & 8 & 7.4 & 96 & 39.0 & 18 & 12.7 & 0 & 0 & & \\
\hline
\end{tabular}

sleep disturbance with annoyance rather than with noise level or source, which gives support to the results of this study.

Moreover, the perception of traffic noise at home and rating of residence as noisy indicates the poor environmental quality of the area (Cassina et al. 2017). Therefore, while evaluating the acoustic quality of an urban area in the general and noisesensitive area in particular, correlating noise perception at home and tranquillity rating with traffic noise-induced annoyance should be given due importance. ESM S1

\section{Suggestions for mitigating the road traffic noise levels}

Studies have found that traffic-induced noise accounts for $80 \%$ of all the communal noise sources, out of which RTN accounts for $79 \%$ (Grubesa and Suhanek 2021). Noise emanating from the vehicles moving on the road is due to the "type of vehicle", "friction between the tires and road surface", and "driving style and driving behaviour". Therefore, while controlling for the RTN, contributions from these three sources 
Table 11 Multivariate logistic regression analysis with highly annoyed being the outcome variable for both verbal and numerical scales

\begin{tabular}{|c|c|c|c|c|c|c|}
\hline \multirow[t]{2}{*}{ Variable } & \multicolumn{3}{|c|}{$\begin{array}{l}\text { Model } 1 \\
\text { (based on verbal annoyance scale) }\end{array}$} & \multicolumn{3}{|c|}{$\begin{array}{l}\text { Model } 2 \\
\text { (based on numerical annoyance scale) }\end{array}$} \\
\hline & OR & $95 \% \mathrm{CI}$ & $\mathrm{p}$ value & OR & $95 \% \mathrm{CI}$ & $\mathrm{p}$ value \\
\hline \multicolumn{7}{|l|}{ Area type } \\
\hline Quiet $^{\mathrm{a}}$ & 1 & & & 1 & & \\
\hline Noisy & 4.06 & $2.79-5.88$ & $<0.001$ & 3.93 & $2.61-5.94$ & $<0.001$ \\
\hline \multicolumn{7}{|l|}{ Sensitivity } \\
\hline Not sensitive ${ }^{a}$ & 1 & & & 1 & & \\
\hline Sensitive & 3.98 & $3.79-8.34$ & 0.034 & 3.92 & $3.59-7.86$ & $<0.001$ \\
\hline \multicolumn{7}{|l|}{ Residence period } \\
\hline 1 to 2 (years) ${ }^{\mathrm{a}}$ & 1 & & & 1 & & \\
\hline 2 to 5 (years) & 0.49 & $0.18-1.41$ & 0.187 & 0.47 & $0.14-1.62$ & 0.195 \\
\hline$>5$ (years) & 0.76 & $0.27-2.18$ & 0.619 & 0.71 & $0.32-2.62$ & 0.618 \\
\hline \multicolumn{7}{|l|}{ Gender } \\
\hline Male $^{\mathrm{a}}$ & 1 & & & 1 & & \\
\hline Female & 1.34 & $0.75-2.27$ & 0.291 & 1.07 & $0.62-1.72$ & 0.769 \\
\hline \multicolumn{7}{|l|}{ Sleep quality } \\
\hline Poor & 3.94 & $2.13-9.97$ & $<0.001$ & 3.91 & $2.04-9.34$ & $<0.001$ \\
\hline Excellent $\mathrm{t}^{\mathrm{a}}$ & 1 & & & 1 & & \\
\hline \multicolumn{7}{|c|}{ Noise perception at home } \\
\hline $\mathrm{No}^{\mathrm{a}}$ & 1 & & & 1 & & \\
\hline Yes & 3.15 & $1.60-6.31$ & $<0.001$ & 3.13 & $1.32-6.52$ & $<0.001$ \\
\hline
\end{tabular}

${ }^{\text {a }}$ Reference group

should be given due consideration. In this direction, some of the measures that can be suggested include:

(a) Proper planning of the "newly developing" and "to be developed" areas such that the residential areas and transportation infrastructure do not lie close to each other.

(b) Building codes can be modified such that noiseattenuating materials like bamboo, coco fibres, and recycled rubber, which have no health effects and are easily available, can be promoted for usage in the construction of buildings (Schiavi et al. 2006).

(c) Implementation of quiet road surfaces has also shown promising results. The usage of thin asphalt layers, stone mastic asphalt, and double-layered porous asphalt, owing to their low to moderate porosity, has shown acoustic absorbing properties (Teti et al. 2020). But the impediment in their large-scale usage is the high costs of maintenance and repair.

(d) The introduction of electric vehicles can also help in improving the acoustic environment of an area. Electrical vehicles generally produce noise levels up to $6 \mathrm{~dB}(\mathrm{~A})$ lower than conventional vehicles. However, the effectiveness has been found at lower speeds only (Grubesa and Suhanek 2021). Besides, the potential risk for pedestrians and bicyclists and high initial investments restrict their usage on a large scale. (e) Introduction of a "smart traffic management" policy with centrally controlled traffic signals and sensors can regulate the traffic movement following the existing state of the roads in the cities. This can result in fewer congestion events and thus reduce the honking phenomenon, especially in developing countries.

(f) Usage of natural noise barriers like vegetation has also proven to be a significant noise-attenuating measure (Fang and Ling 2003). An additional advantage is the improvement of the landscape of the area due to vegetation and also the low maintenance costs associated with it.

It is imperative to mention that the measures suggested are not the only solutions; rather, there are opportunities and prospects for the progress and development of new and existing methods.

\section{Conclusions}

The present study attempts to evaluate the risk factors concerning traffic noise induced annoyance. Living in noisy areas, being sensitive to noise, reporting poor sleep quality, and the perception of traffic noise at home/workplace were found to be significant predictors for the traffic noise induced 
annoyance. The noise map, as well as the façade map, was developed for the study area, and the exposure levels were determined. No such previous studies under the Indian context were found during the literature survey where noise levels were depicted using noise maps and façade maps. The respondents reported disagreement with the statements made regarding the health impacts of traffic noise except the stress statement. The study supports the importance of framing the guidelines about environmental noise levels, given the ample evidence of noise pollution in the noise-sensitive area of this study. The reporting of noise perception at home and rating the environment as noisy are suggestive of the poor acoustical quality of the area. The study also supports the fact that not only should the effects of noise be gauged in terms of the auditory effects but also the psychological impacts of noise should be given due consideration. The study also revealed that despite having a higher literacy rate, the awareness levels concerning traffic noise health effects are lacking. The study proposes that awareness drives, conducted in close coordination between health and environment-related agencies, should be held on a large scale to enlighten the population about the possible health outcomes due to traffic noise exposure as well as the various measures that can help in reducing the exposure. The study also emphasizes the need for framing strict regulations around sensitive areas like hospitals, schools, residential areas, and public libraries, so that good public health, a better quality of life, and a healthier environment can be ensured.

Supplementary Information The online version contains supplementary material available at https://doi.org/10.1007/s11356-021-15208-3.

Acknowledgements The authors would like to thank the Traffic and Transportation planning section of the Department of Civil Engineering, NIT Srinagar, for providing the necessary logistics for conducting the study. We express a deep sense of gratitude to Mohammad Idrees Gilani for helping in data collection.

We would also like to thank the anonymous reviewers for their valuable suggestions and comments for improving the quality of the manuscript.

Availability of data and materials The datasets generated during the current study are not publicly available due to their usage in another study, which is part of the research work currently in progress, but are available from the corresponding author on reasonable request.

Author contribution TAG was associated with data collection, noise modelling, and article preparation work. MSM was associated with the review and correction process. All the authors read and approved the final manuscript.

\section{Declarations}

Ethics approval The study was approved by the ethical committee at NIT Srinagar.

Consent to participate Verbal consent was taken from all the participants of the survey.
Consent for publication Not applicable

Competing interests The authors declare no competing interests.

\section{References}

Agarwal S, Swami B (2011) Road traffic noise, annoyance and community health survey - a case study for an Indian city. Noise Heal 13: 272-276. https://doi.org/10.4103/1463-1741.82959

Ali SA, Tamura A (2003) Road traffic noise levels, restrictions and annoyance in Greater Cairo, Egypt. Appl Acoust 64:815-823. https:// doi.org/10.1016/S0003-682X(03)00031-8

Babisch W (2002) The noise/stress concept, risk assessment and research needs. Noise Health 4:1-11

Babisch W (2005) Noise and health. Environ Health Perspect 113:14-15

Babisch W, Neuhauser H, Thamm M, Seiwert M (2009) Blood pressure of 8-14 year old children in relation to traffic noise at home-results of the German Environmental Survey for Children (GerES IV). Sci Total Environ 407:5839-5843. https://doi.org/10.1016/j.scitotenv. 2009.08.016

Banerjee D (2012) Research on road traffic noise and human health in India: review of literature from 1991 to current. Noise Health 14: 113-118. https://doi.org/10.4103/1463-1741.97255

Banerjee D (2013) Road traffic noise exposure and annoyance: a crosssectional study among adult Indian population. Noise Heal 15:342346. https://doi.org/10.4103/1463-1741.116583

Basner M, McGuire S (2018) WHO environmental noise guidelines for the European region: a systematic review on environmental noise and effects on sleep. Int J Environ Res Public Health 15:519. https:// doi.org/10.3390/ijerph15030519

Basner M, Müller U, Elmenhorst E-M (2011) Single and combined effects of air, road, and rail traffic noise on sleep and recuperation. Sleep 34:11-23. https://doi.org/10.1093/sleep/34.1.11

Basner M, Babisch W, Davis A, Brink M, Clark C, Janssen S, Stansfeld S (2014) Auditory and non-auditory effects of noise on health. Lancet 383:1325-1332. https://doi.org/10.1016/S0140-6736(13)61613-X

Beheshti MH, Taban E, Samaei SE, Faridan M, Khajehnasiri F, Khaveh LT, Jebeli MB, Mehri A, Tajpoor A (2019) The influence of personality traits and gender on noise annoyance in laboratory studies. Personal Individ Differ 148:95-100. https://doi.org/10.1016/j.paid. 2019.05.027

Bianco F, Fredianelli L, Lo Castro F, Gagliardi P, Fidecaro F, Licitra G (2020) Stabilization of a p-u sensor mounted on a vehicle for measuring the acoustic impedance of road surfaces. Sensors (Basel) 20: 1239. https://doi.org/10.3390/s20051239

Brown AL, van Kamp I (2017) WHO environmental noise guidelines for the European region: a systematic review of transport noise interventions and their impacts on health. Int J Environ Res Public Health 14:873. https://doi.org/10.3390/ijerph14080873

Cassina L, Fredianelli L, Menichini I, Chiari C, Licitra G (2017) Audiovisual preferences and tranquillity ratings in urban areas. Environments 5:1. https://doi.org/10.3390/environments5010001

Clark C, Sbihi H, Tamburic L, Brauer M, Frank LD, Davies HW (2017) Association of Long-term exposure to transportation noise and traffic-related air pollution with the incidence of diabetes: a prospective cohort study. Environ Health Perspect 125:087025. https://doi. org/10.1289/EHP1279

Cohen J (1988) Statistical pwer analysis for the behavioral sciences, 2nd edn. LAWRENCE ERLBAUM ASSOCIATES, New York

de León G, Del Pizzo A, Teti L et al (2020) Evaluation of tyre/road noise and texture interaction on rubberised and conventional pavements using CPX and profiling measurements. Road Mater Pavement Des 21:S91-S102. https://doi.org/10.1080/14680629.2020.1735493 
de Paiva Vianna KM, Alves Cardoso MR, Rodrigues RMC (2015) Noise pollution and annoyance: an urban soundscapes study. Noise Health 17:125-133. https://doi.org/10.4103/1463-1741.155833

Debnath A, Singh PK (2018) Environmental traffic noise modelling of Dhanbad township area - a mathematical based approach. Appl Acoust 129:161-172. https://doi.org/10.1016/j.apacoust.2017.07. 023

Del Pizzo A, Teti L, Moro A et al (2020) Influence of texture on tyre road noise spectra in rubberized pavements. Appl Acoust 159:107080. https://doi.org/10.1016/j.apacoust.2019.107080

Dratva J, Zemp E, Felber Dietrich D et al (2010) Impact of road traffic noise annoyance on health-related quality of life: results from a population-based study. Qual Life Res 19:37-46. https://doi.org/ 10.1007/s11136-009-9571-2

Dratva J, Phuleria HC, Foraster M, Gaspoz JM, Keidel D, Künzli N, Liu LJS, Pons M, Zemp E, Gerbase MW, Schindler C (2012) Transportation noise and blood pressure in a population-based sample of adults. Environ Health Perspect 120:50-55. https://doi.org/10. 1289/ehp. 1103448

Essandoh PK, Armah FA (2011) Determination of ambient noise levels in the main commercial area of Cape Coast, Ghana. Res J Environ Earth Sci 3:637-644

European Environmental Agency Report (2014) Noise in Europe 2014

Fang C-F, Ling D-L (2003) Investigation of the noise reduction provided by tree belts. Landsc Urban Plan 63:187-195. https://doi.org/10. 1016/S0169-2046(02)00190-1

Foraster M, Eze IC, Vienneau D, Schaffner E, Jeong A, Héritier H, Rudzik F, Thiesse L, Pieren R, Brink M, Cajochen C, Wunderli JM, Röösli M, Probst-Hensch N (2018) Long-term exposure to transportation noise and its association with adiposity markers and development of obesity. Environ Int 121:879-889. https://doi.org/ 10.1016/j.envint.2018.09.057

Fyhri A, Klaeboe R (2009) Road traffic noise, sensitivity, annoyance and self-reported health-a structural equation model exercise. Environ Int 35:91-97. https://doi.org/10.1016/j.envint.2008.08.006

Gilani TA, Mir MS (2021) Association of road traffic noise exposure and prevalence of coronary artery disease: a cross-sectional study in North India. Environ Sci Pollut Res Int. https://doi.org/10.1007/ s11356-021-14582-2

Grubesa S, Suhanek M (2021) Traffic noise. Noise and environment. IntechOpen, In, pp 137-144

Halperin D (2014) Environmental noise and sleep disturbances: a threat to health? Sleep Sci 7:209-212. https://doi.org/10.1016/j.slsci.2014. 11.003

Hamad K, Ali Khalil M, Shanableh A (2017) Modeling roadway traffic noise in a hot climate using artificial neural networks. Transp Res Part D Transp Environ 53:161-177. https://doi.org/10.1016/j.trd. 2017.04.014

Hammer MS, Swinburn TK, Neitzel RL (2014) Environmental noise pollution in the United States: developing an effective public health response. Environ Health Perspect 122:115-119. https://doi.org/10. 1289/ehp. 1307272

Hänninen O, Knol AB, Jantunen M, Lim TA, Conrad A, Rappolder M, Carrer P, Fanetti AC, Kim R, Buekers J, Torfs R, Iavarone I, Classen T, Hornberg C, Mekel OCL, the EBoDE Working Group (2014) Environmental burden of disease in Europe: assessing nine risk factors in six countries. Environ Health Perspect 122:439-446. https:// doi.org/10.1289/ehp. 1206154

Héritier H, Vienneau D, Foraster M et al (2017) Transportation noise exposure and cardiovascular mortality: a nationwide cohort study from Switzerland. Eur J Epidemiol 32:307-315. https://doi.org/10. 1007/s10654-017-0234-2

Ising H, Kruppa B (2004) Health effects caused by noise: evidence in the literature from the past 25 years. Noise Health 6:5-13
ISO (2003) ISO 1996-1 Acoustics - description, measurement and assessment of environmental noise - part 1: basic quantities and assessment procedures; 2003

ISO (2007) ISO 1996-2. Acoustics - description, measurement and assessment of environmental noise - part 2: determination of environmental noise levels, 2007

Jagniatinskis A, Fiks B, Zaporozhets O, van Oosten N (2016) Annual noise assessment in the vicinity of airports with different flights' intensity. Appl Acoust 101:168-178. https://doi.org/10.1016/j. apacoust.2015.08.017

Jones K (2010) Environmental noise and health: a review. Ercd Report 0907:1-46

Jones S, Tefe M, Appiah-Opoku S (2015) Incorporating stakeholder input into transport project selection - a step towards urban prosperity in developing countries? Habitat Int 45:20-28. https://doi.org/10.1016/ j.habitatint.2014.06.017

Khaiwal R, Singh T, Tripathy JP, Mor S, Munjal S, Patro B, Panda N (2016) Assessment of noise pollution in and around a sensitive zone in North India and its non-auditory impacts. Sci Total Environ 566567:981-987. https://doi.org/10.1016/j.scitotenv.2016.05.070

Lee S (2018) Transport policies, induced traffic and their influence on vehicle emissions in developed and developing countries. Energy Policy 121:264-274. https://doi.org/10.1016/j.enpol.2018.06.035

Lekaviciute J, Argalasova Sobotova L (2013) Environmental noise and annoyance in adults: research in central, eastern and south-eastern Europe and newly independent states. Noise Heal 15:42-54. https:// doi.org/10.4103/1463-1741.107153

Leon Bluhm G, Berglind N, Nordling E, Rosenlund M (2006) Road traffic noise and hypertension. Occup Environ Med 64:122-126. https://doi.org/10.1136/oem.2005.025866

Lercher P, Evans GW, Meis M (2003) Ambient noise and cognitive processes among primary schoolchildren. Environ Behav 35:725735. https://doi.org/10.1177/0013916503256260

Li H-J, Yu W-B, Lu J-Q, Zeng L, Li N, Zhao YM (2008) Investigation of road-traffic noise and annoyance in Beijing: a cross-sectional study of 4th Ring Road. Arch Environ Occup Health 63:27-33. https:// doi.org/10.3200/AEOH.63.1.27-33

Licitra G, Teti L, Cerchiai M, Bianco F (2017) The influence of tyres on the use of the CPX method for evaluating the effectiveness of a noise mitigation action based on low-noise road surfaces. Transp Res Part D Transp Environ 55:217-226. https://doi.org/10.1016/j.trd.2017. 07.002

Mehdi MR, Kim M, Seong JC, Arsalan MH (2011) Spatio-temporal patterns of road traffic noise pollution in Karachi, Pakistan. Environ Int 37:97-104. https://doi.org/10.1016/j.envint.2010.08. 003

Méline J, Van Hulst A, Thomas F et al (2013) Transportation noise and annoyance related to road traffic in the French RECORD study. Int J Health Geogr 12:44. https://doi.org/10.1186/1476-072X-12-44

Miedema HM, Oudshoorn CG (2001) Annoyance from transportation noise: relationships with exposure metrics DNL and DENL and their confidence intervals. Environ Health Perspect 109:409-416. https:// doi.org/10.1289/ehp.01109409

Minichilli F, Gorini F, Ascari E, Bianchi F, Coi A, Fredianelli L, Licitra G, Manzoli F, Mezzasalma L, Cori L (2018) Annoyance judgment and measurements of environmental noise: a focus on Italian secondary schools. Int J Environ Res Public Health 15:208. https://doi. org/10.3390/ijerph15020208

Ministry of Road Transport and Highways (2011) Road transport year book (2011-12). Minist Road Transp Highw 154

Murphy E, Douglas O (2018) Population exposure to road traffic noise: experimental results from varying exposure estimation approaches. Transp Res Part D Transp Environ 58:70-79. https://doi.org/10. 1016/j.trd.2017.11.006

Mushtaq J, Dar AQ, Ahsan N (2020) Spatial-temporal variations and forecasting analysis of municipal solid waste in the mountainous 
city of north-western Himalayas. SN Appl Sci 2:1161. https://doi. org/10.1007/s42452-020-2975-x

Muzet A (2007) Environmental noise, sleep and health. Sleep Med Rev 11:135-142. https://doi.org/10.1016/j.smrv.2006.09.001

Ndrepepa A, Twardella D (2011) Relationship between noise annoyance from road traffic noise and cardiovascular diseases: a meta-analysis. Noise Health 13:251-259. https://doi.org/10.4103/1463-1741. 80163

Nicole W (2013) Road traffic noise and diabetes: long-term exposure may increase disease risk. Environ Health Perspect 121:2013. https://doi.org/10.1289/ehp.121-a60

Okokon EO, Yli-Tuomi T, Turunen AW, Tiittanen P, Juutilainen J, Lanki $\mathrm{T}$ (2018) Traffic noise, noise annoyance and psychotropic medication use. Environ Int 119:287-294. https://doi.org/10.1016/j.envint. 2018.06.034

OUIS D (2001) Annoyance from road traffic noise: a review. J Environ Psychol 21:101-120. https://doi.org/10.1006/jevp.2000.0187

Paiva KM, Cardoso MRA, Zannin PHT (2019) Exposure to road traffic noise: annoyance, perception and associated factors among Brazil's adult population. Sci Total Environ 650:978-986. https://doi.org/10. 1016/j.scitotenv.2018.09.041

Park SH, Lee PJ, Jeong JH (2018a) Effects of noise sensitivity on psychophysiological responses to building noise. Build Environ 136: 302-311. https://doi.org/10.1016/j.buildenv.2018.03.061

Park T, Kim M, Jang C, Choung T, Sim KA, Seo D, Chang S (2018b) The public health impact of road-traffic noise in a highly-populated city, Republic of Korea: annoyance and sleep disturbance. Sustainability 10:2947. https://doi.org/10.3390/su10082947

Pathak V, Tripathi BD, Kumar MV (2008) Evaluation of traffic noise pollution and attitudes of exposed individuals in working place. Atmos Environ 42:3892-3898. https://doi.org/10.1016/j.atmosenv. 2007.12.070

Praticò FG (2014) On the dependence of acoustic performance on pavement characteristics. Transp Res Part D Transp Environ 29:79-87. https://doi.org/10.1016/j.trd.2014.04.004

Praticò FG, Anfosso-Lédée F (2012) Trends and issues in mitigating traffic noise through quiet pavements. Procedia Soc Behav Sci 53: 203-212. https://doi.org/10.1016/j.sbspro.2012.09.873

Praticò FG, Fedele R, Pellicano G (2021) Monitoring road acoustic and mechanical performance. In: Rizzo P, Milazzo A (eds) . Springer International Publishing, Cham, pp 594-602

Pucher J, Korattyswaroopam N, Ittyerah N (2004) The crisis of public transport in India: overwhelming needs but limited resources. J Public Transp 7:1-20. https://doi.org/10.5038/2375-0901.7.4.1

Rahmani S, Mousavi SM, Kamali MJ (2011) Modeling of road-traffic noise with the use of genetic algorithm. Appl Soft Comput 11:10081013. https://doi.org/10.1016/j.asoc.2010.01.022

Roswall N, Raaschou-Nielsen O, Ketzel M, Overvad K, Halkjær J, Sørensen M (2017) Modeled traffic noise at the residence and colorectal cancer incidence: a cohort study. Cancer Causes Control 28: 745-753. https://doi.org/10.1007/s10552-017-0904-0

Ruiz-Padillo A, Ruiz DP, Torija AJ, Ramos-Ridao Á (2016) Selection of suitable alternatives to reduce the environmental impact of road traffic noise using a fuzzy multi-criteria decision model. Environ Impact Assess Rev 61:8-18. https://doi.org/10.1016/j.eiar.2016.06. 003

Rylander R (2004) Physiological aspects of noise-induced stress and annoyance. Journal of Sound and Vibration, In, pp 471-478
Ryu JK, Jeon JY (2011) Influence of noise sensitivity on annoyance of indoor and outdoor noises in residential buildings. Appl Acoust 72: 336-340. https://doi.org/10.1016/j.apacoust.2010.12.005

Schiavi A, Belli AP, Corallo M, Russo F (2006) Acoustical performance characterization of sustainable materials used under floating floors in dwellings. EURONOISE 2006 - 6th Eur Conf Noise Control Adv Solut Noise Control

Seidman MD, Standring RT (2010) Noise and quality of life. Int J Environ Res Public Health 7:3730-3738. https://doi.org/10.3390/ ijerph7103730

Shukla AK, Jain SS, Parida M, Srivastava JB (2009) Performance of FHWA model for predicting traffic noise: a case study of Metropolitan city, Lucknow (India). Transport 24:234-240. https://doi.org/10.3846/1648-4142.2009.24.234-240

Sieber C, Ragettli MS, Brink M, Olaniyan T, Baatjies R, Saucy A, Vienneau D, Probst-Hensch N, Dalvie MA, Röösli M (2018) Comparison of sensitivity and annoyance to road traffic and community noise between a South African and a Swiss population sample. Environ Pollut 241:1056-1062. https://doi.org/10.1016/j. envpol.2018.06.007

Stansfeld SA, Matheson MP (2003) Noise pollution: non-auditory effects on health. Br Med Bull 68:243-257. https://doi.org/10.1093/bmb/ $\operatorname{ldg} 033$

Stansfeld S, Haines M, Brown B (2000) Noise and health in the urban environment. Rev Environ Health 15:43-82. https://doi.org/10. 1515/reveh.2000.15.1-2.43

Teti L, de León G, Del Pizzo A et al (2020) Modelling the acoustic performance of newly laid low-noise pavements. Constr Build Mater 247:118509. https://doi.org/10.1016/j.conbuildmat.2020. 118509

Thakre C, Laxmi V, Vijay R, Killedar DJ, Kumar R (2020) Traffic noise prediction model of an Indian road: an increased scenario of vehicles and honking. Environ Sci Pollut Res Int 27:38311-38320. https:// doi.org/10.1007/s11356-020-09923-6

Traoré S (2019) Residential location choice in a developing country: what matter? A choice experiment application in Burkina Faso. For Policy Econ 102:1-9. https://doi.org/10.1016/j.forpol.2019.01.021

van den Berg F, Verhagen C, Uitenbroek D (2014) The relation between scores on noise annoyance and noise disturbed sleep in a public health survey. Int J Environ Res Public Health 11:2314-2327. https://doi.org/10.3390/ijerph110202314

van Kempen E, Babisch W (2012) The quantitative relationship between road traffic noise and hypertension. J Hypertens 30:1075-1086. https://doi.org/10.1097/HJH.0b013e328352ac54

van Kempen EEMM, Kruize H, Boshuizen HC, Ameling CB, Staatsen BAM, de Hollander AEM (2002) The association between noise exposure and blood pressure and ischemic heart disease: a metaanalysis. Environ Health Perspect 110:307-317. https://doi.org/10. 1289/ehp.02110307

Vastfjall D (2002) Influences of current mood and noise sensitivity on judgments of noise annoyance. Aust J Psychol 136:357-370. https:// doi.org/10.1080/00223980209604163

WHO (2011). Burden of disease from environmental noise : quantification of Healthy Life Years lost in Europe. Copenhagen: The WHO European Centre for Environment and Health, Bonn Office, WHO Regional Office

Publisher's note Springer Nature remains neutral with regard to jurisdictional claims in published maps and institutional affiliations. 